\title{
Personality and Functional Limitations: Investigating the Mediating Effect of Positive Social Exchanges
}

Priyanka S. Mehta

Follow this and additional works at: https://researchrepository.wvu.edu/etd

\section{Recommended Citation}

Mehta, Priyanka S., "Personality and Functional Limitations: Investigating the Mediating Effect of Positive Social Exchanges" (2018). Graduate Theses, Dissertations, and Problem Reports. 6209.

https://researchrepository.wvu.edu/etd/6209

This Thesis is protected by copyright and/or related rights. It has been brought to you by the The Research Repository @ WVU with permission from the rights-holder(s). You are free to use this Thesis in any way that is permitted by the copyright and related rights legislation that applies to your use. For other uses you must obtain permission from the rights-holder(s) directly, unless additional rights are indicated by a Creative Commons license in the record and/ or on the work itself. This Thesis has been accepted for inclusion in WVU Graduate Theses, Dissertations, and Problem Reports collection by an authorized administrator of The Research Repository @ WVU. For more information, please contact researchrepository@mail.wvu.edu. 
Personality and Functional Limitations:

Investigating the Mediating Effect of Positive Social Exchanges

Priyanka S. Mehta

Thesis submitted to

The Eberly College of Arts and Sciences

At West Virginia University

In partial fulfillment of the requirements

for the degree of

Master of Science
in
Psychology

Nicholas A. Turiano, Ph.D., Chair

Julie Hicks Patrick, Ph.D.

Barry Edelstein, Ph.D.

\section{Department of Psychology \\ Morgantown, West Virginia 2017}

Keywords: personality, positive social exchanges, perceived social support, functional limitations, ageing

Copyright 2018 Priyanka S. Mehta 


\begin{abstract}
Personality and Functional Limitations:

Investigating the Mediating Effect of Positive Social Exchanges
\end{abstract}

Priyanka S. Mehta

Research suggests a link between personality traits and various health outcomes. There is now a need to understand why this association exists by investigating potential underlying mechanisms. The current study investigated a potential mechanism that has not received much attention, positive social exchanges (PSS). PSS have been linked to health in various studies, but more research is needed to understand its association with health. The current study utilized data from 6,095 community-dwelling adults from the National Study of Midlife in the United States (MIDUS Wave 1; ages 20-75; $M_{\text {age }}=46.83, S D=12.90$ ). Using the Hayes PROCESS macro, we investigated whether PSS mediated the association between the Big Five personality traits (i.e. conscientiousness, neuroticism, extraversion, agreeableness, openness to experience) and functional limitations. The associations between neuroticism, conscientiousness, extraversion, and agreeableness and functional limitations were significantly mediated by PSS. Exploratory age moderation revealed that age significantly moderated the association between neuroticism, conscientiousness, and extraversion with functional limitations such that the association was stronger at older ages. Through further analyses of these paths, it is possible to get a stronger understanding of how these processes work. 


\section{Table of Contents}

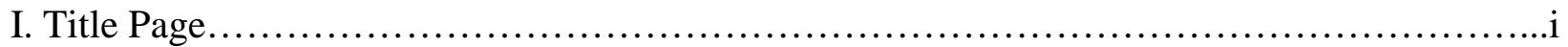

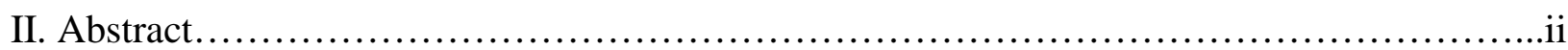

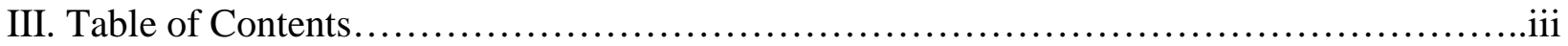

II. Introduction....................................................................................

II. Statement of the Problem..................................................................

A. Research Questions and Hypotheses..............................................16

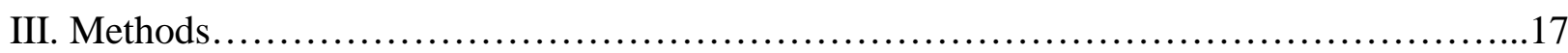

A. Study Sample and Design......................................................

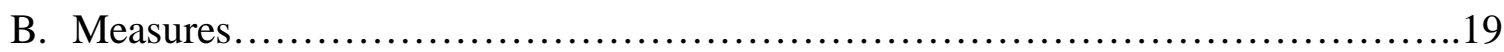

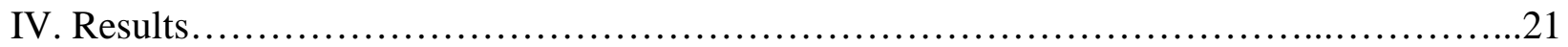

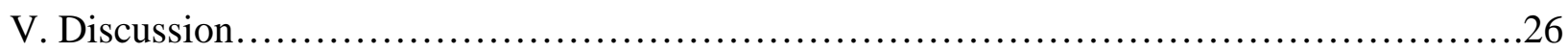

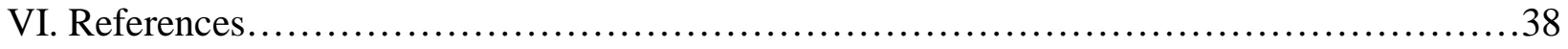

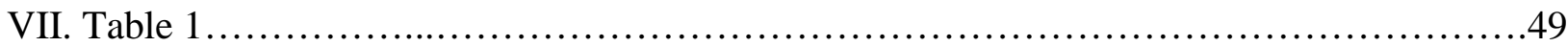

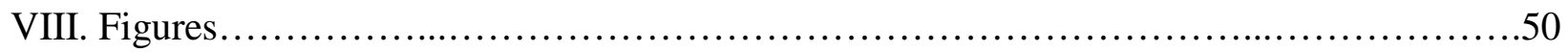

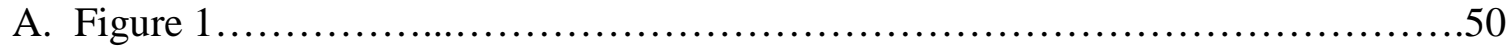

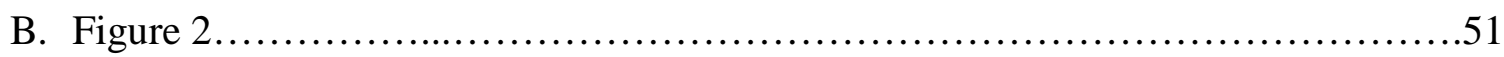

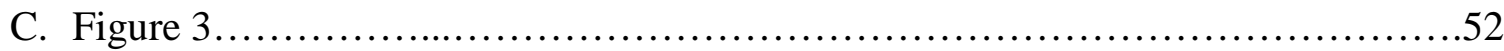

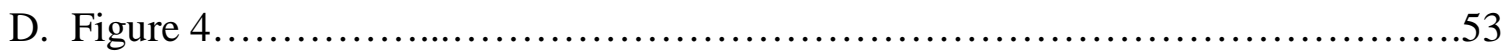

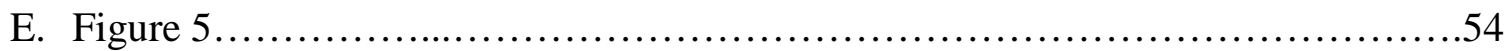

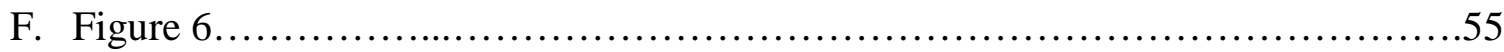

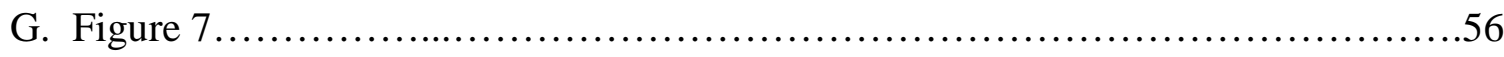

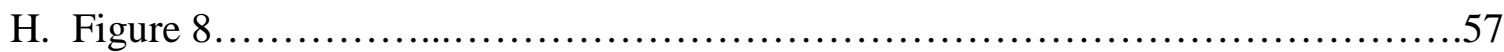


VIII. Appendices....................................................................58

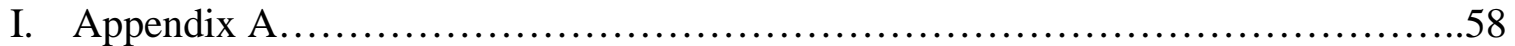

J. Appendix B.......................................................59

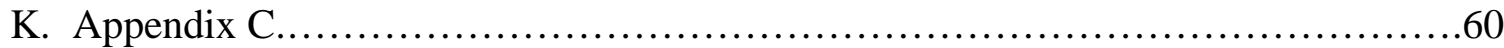

L. Appendix D.......................................................61

M. Appendix E..........................................................62

N. Appendix F.........................................................63 


\section{Personality and Functional Limitations:}

\section{Investigating the Mediating Effect of Positive Social Exchanges}

The older adult population is increasing rapidly and with it, the nation's healthcare costs. As age increases, physical health issues become more pronounced resulting in older adults facing more health related problems that need medical attention (Morack, Infurma, Ram \& Gerstorf, 2013). Due to these increased rates of health issues, attention in the field has shifted to understanding psychosocial factors associated with health declines. Individuals’ personality traits are one of the key factors associated with these health declines (Hampson \& Friedman, 2008). Research has clearly demonstrated that personality is associated with numerous types of health outcomes such as self-rated health (Idler \& Benyamini, 1997), chronic disease progression such as chronic inflammation and obesity (Sutin, Zonderman, Ferrucci \& Terracciano, 2013), and mortality risk (Turiano, Chapman, Gruenewald \& Mroczek, 2015). With ample evidence linking personality with various health outcomes, there is now a growing interest in understanding the mechanisms that explain exactly why personality predicts health over the life span (Friedman \& Kern, 2014).

The current study will explore one potential mechanism involved in the association between personality and health, positive social exchanges (PSS), an essential aspect of social relationships. This construct involves the confidence, respect, and aid (Ingersoll-Dayton, Morgan \& Antonucci, 1997) that are important aspects of everyday social situations (Mund \& Neyer, 2014) and can help individuals cope with stressful circumstances and avoid the feeling of loneliness (Liu \& Rook, 2013). The goal of the present study is to test whether the PSS one receives from various sources of their social network mediates the association between personality and functional health. Such research will provide a more nuanced understanding of 
how psychological factors influence both social interactions and functional health as individuals' age, which is a necessary foundation for future prevention and intervention efforts aimed at improving health and longevity.

\section{Personality: The Big Five}

Personality encompasses an individual's relatively enduring patterns of thoughts, behaviors and emotions that make that person unique. This construct is different, but similar to temperament, which is primarily biologically based and usually assessed in infants and children (Clark \& Watson, 2008). However, during late childhood and early adolescence, measures of personality are more common as this taxonomy includes more environmental influences, compared to measures of temperament. To quantify personality, researchers have used many different conceptualizations. A common framework is called the Five Factor Model (Goldberg, 1981; Ibrahim et al., 2015). Often referred to as the Big Five, this taxonomy suggests that an individual's personality can be best represented by five distinct, yet related, traits: neuroticism, conscientiousness, extraversion, agreeableness, and openness.

The Big Five were developed through extensive factor analytic work dating back to the 1930’s (Allport \& Odbert, 1936). Participants were given lists of adjectives upwards of 18,000 items and asked to rate how much each adjective described them. With the help of various researchers, studies, and factor analyses, these long lists of adjectives were narrowed into smaller clusters. Early research utilized 35 clusters from 4,500 of the original terms (Cattell, 1943; Cattell, 1945). However, these were further narrowed down into five main factors (Goldberg, 1990), which inevitably set the foundation for the Big Five personality characteristics (McCrae \& Costa, 1987; Goldberg, 1981). Individuals scoring higher in conscientiousness are commonly goal-directed, responsible and in control of their impulses, while individuals scoring higher in 
neuroticism often experience negative emotions, such as worry, and emotional instability.

Individuals scoring higher in openness have higher degrees of imagination, unconventionality, creativeness and intellectuality. Extraversion contains various features, including the propensity to be outgoing, active, expressive and social. Lastly, individuals scoring higher in agreeableness tend to be more helpful, warm, sympathetic, and caring. These traits tested with functional limitations to understand their association.

\section{Functional Limitations}

Perceived functional health (referred to as functional limitations throughout in the current study), refers to both basic activities of daily living (ADLs; i.e. bathing or dressing self, walking one block) or instrumental activities of daily living (IADLs; i.e. cooking, housework; Puente, Lindbergh \& Miller, 2014). These limitations are linked to both increases in health care costs and other health concerns such as mortality. Heath care costs increase by $\$ 1,541$ for each ADL and by $\$ 714$ for each IADL community-dwelling individuals who had Azheimer’s disease or other dementias (Hill, Fillit, Thomas, \& Chang, 2006). Functional limitations are an aspect of physical health that can provide vital information about individuals' overall health status. For example, greater functional limitations and resulting dependency has been linked to increased mortality (Reuben, Rubenstein, \& Hirsch, 1992). Medical advances have allowed for longer life spans, however these advances do not always prevent declines in functional health (Puente et al., 2014). Therefore it is crucial to understand what variables are associated with differences in functional limitations.

The accumulation of functional limitations adds to the healthcare costs, therefore, researchers have sought to understand its link to longevity. Older people who have lower health risks (e.g., not smoking, healthy exercise patterns) live longer. Researchers studied if the 
increased longevity predicted more or less functional limitations (Vita, Terry, Hubert, \& Fries, 1998). A longitudinal study was done from $1962\left(M_{a g e}=43\right)$ to $1994\left(M_{\text {age }}=75\right)$ using 1,741 university alumni and findings revealed that people with high health risks during the study had greater functional disability than those with low health risks. People with lower health risks also postponed the onset of disability for more than 5 years and the disability was compressed into fewer years at the end of life allowing the lower risk participants to live longer and healthier lives (Vita et al., 1998). This study had examined health risks linked to health behaviors, but did not account for the role of participants' social environment, which may have also explained why participants had lived longer and healthier versus shorter and unhealthier lives. Consistent with these findings, it is well known that having more functional limitations is a predictor of earlier mortality (Idler, Russel, \& Davis, 2000; Reuben et al., 1992). Using 282 elderly participants (ages 64 and older), researchers conducted longitudinal analyses to determine if functional limitations predicted mortality over 4 years (Reuben et al., 1992). After the 4 -year period, 24\% of participants had died and greater functional limitations significantly predicted an increased risk of death. The good news is that functional limitations have the potential to be prevented or delayed (Glass, Matchar, Belyea, \& Feaussner, 1993). Therefore, investigation in this area on potentially protective factors can provide important information for identifying who is at-risk for functional decline and also information necessary for developing interventions.

\section{Personality and Physical Health}

Personality is a well-known predictor of various physical health problems. For example, findings from the U.S. MIDUS study revealed that higher levels of conscientiousness predicted better self-reported physical health, blood pressure, and health-related work reductions (how many of the past thirty days respondents were limited at work or home because of physical 
health reasons) while higher levels of neuroticism predicted worse health on each outcome (Turiano, Pitzer, Armour, Karlamangla, Ryff, \& Mroczek, 2011). Higher levels of extraversion predicted better physical health, and both higher extraversion and openness predicted fewer work reductions. These findings suggest that personality is linked to a variety of specific physical health and life outcomes, rather than just general self-rated physical health. Other researchers have investigated Australian adults $(N=11,105$, ages 20-79) to assess how changes in personality were related to subjective physical health (Magee, Heaven, \& Miller, 2013). Individuals who became more conscientiousness over the 4-year period experienced better health because of participation in more health-promoting behaviors such as diet and exercise. Individuals who became more extraverted over time experienced better subjective physical health. Neuroticism, agreeableness and openness to experience did not emerge as significant predictors of health in this study. Studying additional health outcomes such as such as functional limitations can allow us to better understand the extent of personality's impact on more specific aspects of physical health. In the current study, self-rated functional limitations, a more direct question about physical functioning, will be analyzed.

In addition to other aspects of physical health, several studies have investigated the link between personality and functional limitations, with a specific focus on older adults. For example, among community dwelling older adults, those scoring higher in openness (Puente et al., 2014; Suchy, Williams, Kraybill, Franchow, \& Butner, 2010), higher in agreeableness and lower in neuroticism (Suchy et al., 2010) had fewer functional limitations. In a study of 65 community dwelling older adults (ages 65-85), higher levels of openness were associated with less functional limitations (Puente et al., 2014). Another study also utilized 65 communitydwelling adults (ages 60-87) and further specified the link because individuals scoring lower in 
openness to experience had more functional limitations (Suchy et al., 2010). Similarly, individuals scoring lower in agreeableness had greater functional limitations. Additionally, individuals higher in neuroticism had more functional limitations. Consistent with other studies, researchers investigating 265 primary care medical patients (ages 60+) found that individuals scoring lower in openness to experience had greater functional limitations (Duberstein et al., 2003). Research with older adults is vital because individuals’ physical health declines in old age, however, it is also important to incorporate more research using a wider variety of participants to understand what factors contribute to functional limitations at all ages in the lifespan (Zimmer \& House, 2003).

In addition to research on community-dwelling older adults and primary care patients, researchers have also studied the association between personality and functional limitations among samples of older adults with specific diseases. Among individuals suffering from Mild Cognitive Impairment or Alzheimer’s disease pathology (Roy et al., 2016). Higher levels of conscientiousness were associated with fewer functional limitations. The researchers indicated that personality was an independent predictor of functional limitations and that early identification of vulnerable people could help delay functional limitations through intervention. There is evidence connecting each personality trait to functional limitations, however more research is needed to uncover which personality traits have strong associations with functional health.

The growing number of older adults in society requires that researchers seek to improve medical knowledge about predictors of functional limitations, thus potentially leading to the reduction of health care costs. The current study examined potential predictors of functional limitations to allow further understanding of why some individuals experience more limitations 
than others. Studies involving various samples have investigated the link between personality and functional health and have supported personality’s predictive ability (Roy et al., 2016; Suchy et al., 2010). While these samples did vary, they were still limited because most studies focused solely on older adults, which limited the generalizability and utility of the research. Additionally, the findings of these studies were not very consistent because they found differences with which personality traits were significantly associated with functional limitations.

\section{Perceived Social Support}

Researchers have indicated that social relationships with other people are an important part of an individuals' environment (Mund \& Neyer, 2014). Social support is the broad term defined in a variety of ways in research such as availability of support, density of network, frequency of network contact, composition of network, instrumental support (i.e., material or financial aid), informational support (i.e., advise and guidance) and emotional support (i.e., expressing care or empathy; Cohen, 2004; Waler \& Lachman, 2000). As social support is such a broad term, researchers have found benefits in examining more specific aspects of the construct (Barrera, 1986; Rook, 1984). Measuring social support can involve various aspects of support, however, these are not always strongly related to one another. As a result, researchers might not know which aspect was strongly related to the variable of interest (Barrera, 1986). Investigating more precise concepts and measures can fit with specific models and predictions, and can potentially allow understanding of what specific aspects of social support are beneficial. One specific aspect of social support, which has not received much attention, is the PSS one has with various members within their social network. PSS involves enacted support, which includes confiding, respecting and aiding someone within social interactions (Ingersoll-Dayton et al., 1997). PSS also involves the perceptions an individual has about their social network and how 
satisfied they are with their relationships (Okun \& Keith, 1998), as well as how much an individual perceives that their social network is caring and understanding (Walen \& Lachman, 2000). Measures of PSS are meant to capture satisfaction with a variety of types of positive interactions and satisfaction with one's social network has been a more reliable predictor of better health than similar measures investigating just the amount of support received (Newsom et al., 2005).

\section{Personality and Perceived Social Support}

PSS can vary from person to person based on the individual's personality. There are three key ways that this occurs, through evoking reactions from others, through exposure to stressful interactions, and through the individual’s own reactivity (Bolger \& Zuckerman, 1995; Caspi, Elder \& Bem, 1987). An individual's personality will evoke different responses from their environment (cumulative continuity), and, more specifically, unintentionally elicit predictable reactions from their social network (interactional continuity; Caspi et al., 1987; Mund \& Neyer, 2014), inevitably influencing their PSS. For example, extraverted individuals are more sociable, display more positive affect and more likely to provide greater PSS (Bowling, Beehr, \& Swader, 2005; Cukrowicz, Franzese, Thorp, Cheavens \& Lynch, 2008; Snyder, 1983). More sociable and more positive individuals were more likely to experience positive social interactions, and individuals who provided greater PSS were more likely receive greater PSS (Bowling et al., 2005; Snyder, 1983). A second pathway personality is associated with PSS is through the stressful situations that one is exposed to or perceives. For example, individuals scoring higher in neuroticism are more likely to expose themselves to situations that are stressful, thus limiting their perception of PSS from others (Bowling et al., 2005). A third pathway involves associations between personality and the reactivity to others and stressful situations. For example, individuals 
higher in neuroticism are more likely to react negatively during social situations, thus evoking less PSS from their network (Felsten, 2002; Wilson, Harris, \& Vazire, 2015). The behavior an individual displays impacts their interactions with others, making more reactive individuals struggle more with social interactions. Researchers have investigated each of these links to understand how personality impacts the individual's environment and support from their social network.

Depending on an individual's personality traits, different reactions will be evoked from an individual's social network altering the frequency of PSS (Caspi et al., 1987). Using longitudinal data from late childhood to adulthood on 214 participants from the Berkeley Guidance Study, researchers found that participants who expressed more uncontrolled and moody behavior in childhood continued to experience similar behavior in adulthood. Since these individuals continued to exhibit those ill-tempered behaviors in adulthood, they experienced worse occupational achievement and were more likely to get divorced - outcomes not indicative of receiving PSS from their social network. In a study that examined more direct connections between personality and evocation in 132 students (ages 18-22) over 18 months, researchers found higher conscientiousness predicted greater closeness with family, agreeableness predicted fewer conflicts with opposite-sex peers and extraversion predicted a greater amount of time spent on social interaction in general (Asendorph \& Wilpers, 1998). Closeness, fewer conflicts and participating in social interactions are all important factors for PSS as PSS reflecst if an individual perceives their social network as caring, respectful, helpful and understanding. These findings further illustrate how personality can influence an individual’s environment via evocation of PSS. 
In addition to evoking responses from others, one’s personality can influence the amount of stressful situations that are experienced. A study using a 28-day daily diary procedure investigating 96 women indicated that individuals who experience less PSS and more chronic stress had worse recovery speed and stronger reactivity when handling daily stressors (Caspi, Bolger, \& Eckenrode, 1987). Therefore, PSS plays an important buffering role as individuals handle stressful circumstances and may impact how individuals handle stress in general. Other researchers tested this more specifically using 104 university students (ages 19-35) to examine links between personality traits and the levels of stressful situations encountered in daily life as well as the level of reactivity individuals experienced. The findings indicated that individuals scoring higher in neuroticism were more vulnerable to daily stressors thus reported more daily stressors. These individuals may experience a greater number of stressors or perceive more situations as stressful. Contrary to these results, individuals scoring higher in conscientiousness experienced fewer stressful circumstances and lower reactivity to daily stressors overall. Additionally, higher levels of agreeableness was protective specifically against social stressors, but not other stressors, and extraversion's facet of positive affect was protective and individuals higher in openness were more reactive to daily stressors. Individuals higher in certain personality traits are more likely to be more vulnerable to stress and this vulnerability could potentially impact their social exchanges because of a lack of self-selection into environments indicative of PSS.

Researchers have also found links between specific personality traits and levels of reactivity, and this association can play an important role in experiencing PSS. For instance, a study on 156 undergraduate students (ages 17 to 25) revealed that individuals scoring higher in neuroticism had higher negative reactivity, or stronger negative reactions to unpleasant 
experiences (Gross, Sutton \& Ketelaar, 1998). Individuals higher in extraversion had higher positive reactivity, meaning they have stronger positive reactions to pleasant experiences. These researchers also indicated that individuals scoring higher in extraversion accumulate a larger social network over time, leading to a higher likelihood of social contact and PSS, which could benefit their coping with stress or occur because of their positivity. Other researchers further illustrated the importance of personality's association with reactivity and social interactions. For instance, a 42-day diary study with married couples asked husbands and wives to respond independently, and observed links between neuroticism and reactivity to stressors (Bolger \& Schilling, 1991). Individuals scoring higher in neuroticism experienced greater exposure and reactivity to daily stressors, especially when the stressor related to interpersonal conflict. These studies indicated that personality traits such as neuroticism linked to higher reactivity and less PSS. Contrary, higher extraversion linked to lower reactivity and more PSS. Additionally, social relationships can be a significant source of stress though PSS can potentially buffer these negative experiences (Ingersoll-Dayton et al., 1997). Personality impacts how we shape our social interactions, therefore those higher in extraversion will likely experience more PSS than others such as those higher in neuroticism (Roberts, Woods \& Caspi, 2008; Caspi et al., 1987).

\section{Perceived Social Support and Physical Health}

Social support research has a long history dedicated to understanding how social interactions are associated with well-being and stress levels. Social interactions can include both positive (e.g., support, companionship) and negative social exchanges (e.g, strain, anger), however researchers in the field have confirmed these are distinct areas of research (IngersollDayton et al., 1997). PSS are generally beneficial interpersonal experiences, which could involve support, receipt of care or affirmation (Windsor et al 2014), and are capable of influencing 
emotional health by providing a buffer against adverse interactions (Rook, 2010) or general stressful circumstances. For instance, in a study using 916 older adults (ages 65-91), PSS were associated with lower levels of loneliness, self-esteem and depression, which are all strongly linked to physical health (Liu \& Rook, 2013). In addition, reducing levels of loneliness as someone ages is especially important because higher levels of loneliness can lead to quicker progression of chronic disease. In a similar study, which examined 2,829 community-dwelling elderly in the Netherlands (ages 55-85), receipt of emotional support and experiencing less loneliness reduced risk of earlier mortality (Penninx, Tilburg, Kriegsman, Deeg, Baeke \& van Eijk, 1997). Emotional support encompasses how much the social network express care or empathy, and PSS involve how caring and understanding individuals perceive their social network to be, making these two constructs closely linked. To reduce loneliness and possibly prevent physical health issues, it is important for individuals to have PSS and perceive their social networks as caring (Liu \& Rook, 2013). With PSS, individuals have a useful buffer to help deal with negative life events and avoid issues such as loneliness as they age, which are associated with negative physical health outcomes.

Studies on PSS have revealed that there is an association with functional health. In one study, using 3,626 community-residing adults (ages 32-84), the researchers indicated that higher PSS had a long-term association with fewer functional limitations (Lachman \& Agrigoroaei, 2010). Another study examining 482 community-dwelling older adult participants longitudinally for two years, investigated the patterns of change that occurred in PSS and functional limitations (Mavandadi, Rook \& Newsom, 2007). Results revealed that majority of the individuals who perceived experiencing many PSS regularly (87.4\%) had little to no disability and possibly even functional recovery over time, while 12.6\% experienced greater functional limitations. 
Functional recovery referred to individuals who has greater functional limitations at Wave 3 of the study, but then showed fewer functional limitations at Wave 5. Based on these findings, the researchers concluded that PSS were protective, and the absence of PSS may lead to greater functional limitations. These studies were an important contribution to the field because of the lack of research connecting PSS and functional limitations. Research examining different sources of PSS has also revealed robustness of associations between PSS and health.

Research supports the fact that different social contacts (e.g., friends, family, partners) have differential effects on these exchanges, though this research is limited and investigation is needed on physical health. One study that looked at the differential impacts of different sources of PSS used a sample of 2,348 adults with a wide age range (ages 25-75), revealed that spouse support was most strongly associated with well-being compared to family and friend support (Walen and Lachman, 2000). Research has indicated that the social exchanges from an individual's primary confident, or closest person, has the greatest impact on their well-being (Kahn \& Antonucci, 1980) and for many people that may be their spouse or partner. With spouses there is also a high degree of familiarity over time, which may contribute to the positive impact it has on well-being (Carstensen, 2006; Windsor, et al., 2014). Other studies have found different sources impact cognitive health. For instance, PSS from friends assisted participants’ episodic memory and PSS from friends and family were associated with less declines in perceptual speed. This may indicate that individuals who have better perceptual speed spend more time outside the home with friends and non-co-resident family (Windsor et al., 2014). This would allow them to engage in a stimulating, potentially intellectual, environment differing from the familiarity provided by spousal interactions. Overall, the source of support does impact wellbeing and cognition therefore different sources could impact related outcomes of health, such as 
functional limitations, differently too. At this time there are no studies found that investigate the role of different sources of PSS on functional health, however, studies have examined other outcomes such as well-being and cognitive health. PSS can have differential associations with other health outcomes; therefore, multiple sources are important for the benefits of PSS. In this study, a composite measure of these various sources was used to encompass the important individuals in the social network.

\section{Personality, Perceived Social Support, and Health: Exploring Mechanisms}

Extant research indicates that there are links between personality traits, social exchanges and health, however there is limited research examining all of these pathways in a single study. Personality influences how individuals react to stressful situations as well as what responses they will evoke from their social networks (Caspi et al., 1987). Perceived social support is an important buffer against the adverse effects of those stressful situations on an individual's physical health, therefore a person who experiences more perceived social support will cope better with stressful situations, potentially preventing physical health problems.

The Transactional Stress Moderation Model (Smith, 2006) highlights how personality’s association with health can be attributed to personality's impact on the frequency, severity and duration of stressful circumstances. This occurs because people appraise stressful situations differently. For example, individuals higher in neuroticism who are more stressed and more reactive would experience stressful circumstances as worse than individuals higher in conscientiousness causing them to worry and stress more. The emotional instability may link to these individuals being more nervous with their social network and they may appraise the network’s behavior more negatively than an individual low in neuroticism (Bowling et al., 2005; Lachman \& Agrigoroaei, 2010). Therefore, these individuals may have more social withdrawal, 
PSS may not occur as often for individuals higher in neuroticism, or might be seen as unhelpful if they do occur, which would link to greater functional limitations because they link to more or continued strain (Mavadadi et al., 2007). Based on these associations, individuals higher in neuroticism experience less PSS and higher functional limitations.

Contrary to neuroticism, the traits conscientiousness, extraversion, agreeableness and openness are linked to more PSS and fewer functional limitations. Individuals higher in conscientiousness are more reliable and responsible, and were more likely to maintain social interactions even when dealing with depression (Cukrowicz et al., 2008). Maintaining these social interactions was important for more PSS. Individuals higher in extraversion show more positive affect and seek more social interaction and provide more positive interactions (Bowling et al., 2005; Cukrowicz, et al., 2008; Snyder, 1983). These factors increase the likelihood of having more social interactions. Extraverted individuals experience more positive affect and less response to aversive stimuli, therefore individuals in extraversion may be more likely to perceive interactions as positive (Bowling et al., 2005; Robinson, Meier \& Vargas, 2005) Similar to extraversion, individuals higher in agreeableness also provide more positive interactions, which is linked to the receipt of more PSS (Bowling et al., 2005). Lastly, there is a lack of research involving openness and PSS, however, individuals higher in openness may be more willing to have interpersonal aid for important tasks (Righetti, Kumashiro, \& Campbell, 2014). PSS allow people to feel cared for, receive various kinds of support, and have companionship, which is beneficial to coping and health (Mavandadi et al., 2007). They promote healthier behaviors, such as higher physical activity, they can reduce stress, and they even can help with recovery from physical issues such as functional limitations because of the security they provide (Mavandadi et al., 2007; Lachman \& Agrigoroaei, 2010; Seeman et al., 1995). This study will examine the 
importance of positive interactions with one's social network by examining the role of PSS in the personality-health association.

\section{Statement of the Problem}

With life expectancy and the older adult population both increasing, there will be more older adults at risk of experiencing physical declines as they age. Although there has been support for health behaviors as possible pathways connecting personality to physical health (Turiano et al., 2013), other pathways need to be explored because health behaviors do not fully explain the association between personality and functional limitations. Researchers have also not uncovered all of the factors that contribute to functional limitations. Personality is one predictor of functional limitations that can be further investigated (Puente et al., 2014). The current study will examine how PSS, a specific component of social relationships, may explain why personality is associated with health via functional ability. Although there is empirical evidence that personality is associated with aspects of social relationships (Caspi et al., 1987; Smith, 2006), and social relationship characteristics are associated with various health outcomes (Cohen, 2004), research is lacking on the integration of both processes. The goal of the present study is to bridge these two distinct areas by examining whether PSS is a pathway that explains how personality predicts functional health in a large sample of adults.

\section{Research Question, Hypotheses, and Proposed Analyses}

\section{Research Questions}

1. Will PSS mediate the association between personality and functional limitations?

Hypothesis. When analyzing the indirect effect of PSS on the personality-functional limitation association, I expect that PSS will significantly mediate the effect for each personality trait. Specifically, higher levels of conscientiousness, agreeableness, openness, and extraversion 
will lead to greater reported PSS, which will be associated with better functional health.

Alternatively, higher neuroticism will predict fewer PSS, which will be associated with poorer functional health.

Analysis. Using the Hayes (2013-2015) PROCESS model, I estimated several different mediational models to examine the significance of the direct, indirect, and total effects of each personality trait on functional health, via PSS. PROCESS is an observed variable path analysis modeling tool for SPSS and SAS (Hayes, 2012). PROCESS is useful for estimating the direct, indirect, and total effects in mediator models, interactions in moderation models, and simple slopes and regions of significance such as with the Johnson-Neyman post-hoc analysis for probing interactions. The indirect effects were conducted using 5,000 bootstrap samples, which was the recommended amount (Hayes, 2009). Statistical significance of the indirect effect was based on whether the 95\% confidence interval of the indirect effect included zero. If the confidence interval did not include zero, indirect effects were deemed statistically significant. There was a total of 5 different models estimated for the mediation analyses. Indirect effects for each personality trait were estimated separately in its own model, while still controlling for the other personality traits. For example, the indirect effect of conscientiousness on functional health, through PSS, was estimated while controlling for demographic factors (e.g., age, gender, marital status, race and education) and the other Big 5 personality traits. This was done for each of the Big 5 personality traits.

\section{Methods}

\section{Sample and Study Design}

Participants included in the current study were enrolled in the National Survey of Midlife Development in the United States (MIDUS) Wave 1, which was collected in 1994-1996 (N = 
7,108). These participants were recruited through a nationally representative random-digitdialing sample. MIDUS is an interdisciplinary longitudinal study investigating midlife development involving a variety of psychological, behavioral and social constructs (for review, see Brim, Ryff, \& Kessler, 2004). Consented participants completed a 30-minute telephone survey and were mailed additional questionnaires that took approximately two hours to complete. If the self-administered questionnaires were not mailed back to the study team then participants were contacted and sent new questionnaires.

The current study did not include data on all 7,108 MIDUS participants because of missing data. The sample included 6,095 participants (ages 20-75; $M_{\text {age }}=46.83, S D=12.90$ ). For these analyses, participants needed to complete the following measures: demographics such as age, sex, race, marital status, and education; the Big Five personality questionnaire; PSS from all sources, and questions regarding functional limitations. If participants did not have a spouse/partner then the composite score was an index of their friend and family support scores. Comparing the participants who were included in the study versus those who had missing data revealed that those included were more likely to be older ( $t=7.32, p<.001)$, female $\left(\chi^{2}=\right.$ 13.77, $p<.001)$, Caucasian $\left(\chi^{2}=26.74, p<.001\right)$, married $\left(\chi^{2}=111.09, p<.001\right)$, more educated ( $t=8.66, p<.001)$, lower on extraversion $(t=-2.14, p<.05)$, had fewer functional limitations $(t=-6.59, p<.001)$ and had more composite PSS $(t=2.39, p<.05)$, but did not significantly differ in agreeableness, neuroticism, conscientiousness, and openness.

\section{Covariates}

All models were adjusted for age, gender, marital status, education and race because of known associations with personality, PSS and health (Goldberg, Sweeney, Merenda, \& Hughes, 1998; Heaven et al., 2006; Shanahan, Hill, Roberts, Eccles \& Friedman, 2012). With regard to 
socio-demographic characteristics of the overall MIDUS Wave 1 sample, the gender distribution of participants was generally balanced, with 53\% female (coded 0) and 47\% male (coded 1). Participants were primarily Caucasian (approximately 93\%, coded 0 and Black and/or African American, Native American or Aleutian Islander/Eskimo, Asian or Pacific Islander, other and multicultural coded as 1). Approximately 70\% of MIDUS participants were married (coded 0) and about 30\% were unmarried (coded 1 represented those widowed, divorced, separated, or never married). Education indexed the highest level of education obtained measured on a 12point scale ranging from 1 (no schooling or some grade school) to 12 (professional degree such as $\mathrm{PhD}$ or $\mathrm{MD})$. Approximately $67 \%$ of the sample had at least some college training. More details on descriptive statistics for all study variables can be found in Table 1.

\section{Predictor Variables}

Personality. The Big Five personality inventory is a 25-item self-administered adjectival scale encompassing five different personality traits: agreeableness, extraversion, neuroticism, conscientiousness and openness to experience (Lachman \& Weaver, 1997). Participants were given each adjective in a list and asked to rate themselves on a 1 (not at all) to 4 (a lot) scale to indicate how much they identified with that trait. Agreeableness was measured using five adjectives (helpful, warm, caring, softhearted, and sympathetic; $\alpha=.81$ ) from the Midlife Development Inventory. Five adjectives (outgoing, friendly, lively, active and talkative; $\alpha=.78$ ) were also used to measure extraversion. Neuroticism was measured using four adjectives (moody, worrying, nervous, and calm; $\alpha=.74$ ) as well as conscientiousness (organized, responsible, hardworking and careless; $\alpha=.58$ ). For both neuroticism and conscientiousness the last adjectives were recoded (calm and careless). Lastly, openness was measured using seven adjectives (creative, imaginative, intelligent, curious, broad-minded, sophisticated and 
adventurous; $\alpha=.78$ ). Each of these personality traits was calculated using the mean across each set of adjectives. A higher mean score indicated a higher level of that personality trait (see Appendix B).

Perceived social support. PSS were measured using a 14-item scale with three subscales: friend support, family support, and spouse or partner support (Schuster, Kessler, \& Aseltine, 1990). The friend support subscale includes 4 -items $(\alpha=.88)$ and asks "How much do your friends really care about you?”, “How much do they understand the way you feel about things?”, “How much can you rely on them for help if you have a serious problem?”, and “How much can you open up to them if you need to talk about your worries?” The family support scale $(\alpha=.84)$ is very similar except the first question begins with "Not including your spouse or partner, how much do members of your family...” The spouse or partner support scale contains six-items $(\alpha=.92)$ asking respondents "How much does your spouse or partner really care about you?”, “How much does he or she understand the way you feel about things?”, “How much does he or she appreciate you?”, “How much do you rely on him or her for help if you have a serious problem?”, “How much can you open up to him or her if you need to talk about your worries?”, and "How much can you relax and be yourself around him or her?” All of the PSS are measured on a scale of 1 (not at all) to 4 (a lot). Calculating the mean of all responses across all three subscales created a mean PSS score $(\alpha=.87)$. Twenty-five percent of participants did not have a spouse/partner so their composite score was calculated from an average of their friend and family support scores $(n=1,532)$. Higher mean scores indicated more PSS (see Appendix C).

\section{Functional Limitations}

To analyze functional limitations, we utilized participants’ ratings on their physical ability to complete nine different activities ( $\alpha=.94$; Ware \& Sherbourne, 1992) including: 
"lifting or carrying groceries, bathing or dressing yourself, climbing several flights of stairs, bending, kneeling, or stooping, walking more than a mile, walking several blocks, walking one block, vigorous activity (e.g. running, lifting heavy objects), and moderate activity (e.g. bowling, vacuuming).” This scale was created from the physical functioning subscale that is part of the SF-36, which was a survey developed for general populations, similar to MIDUS (Lachman \& Agrigoroaei, 2010). Participants responded on a 4-point Likert scale from 1 (not at all) to 4 (a lot). An average score was calculated based on all responses such that higher scores indicated greater functional limitations (see Appendix D).

\section{Results}

\section{Preliminary Analyses}

To ensure data was downloaded accurately from the MIDUS website, all of the variables were checked with the MIDUS codebook to compare n values, means, standard deviations and ranges. To begin data cleaning, I first conducted attrition analyses. I used t-test and chi-square analyses because not all participants completed the study fully. Next, once the data was cleaned I tested appropriate variables for normality by analyzing the skewness and kurtosis. Normality of data was confirmed as skewness and kurtosis values were within acceptable limits between -2 and +2 (George \& Mallery, 2010).

Finally, once univariate analyses were complete, bivariate analyses were completed to determine if variables were correlated appropriately. Correlation analyses were executed between descriptive demographic variables (age, gender, race, marital status and education) and the main variables being tested (personality, PSS and functional limitations; see Appendix F).

The correlations showed that age was significantly positively associated with agreeableness, conscientiousness, Composite PSS and functional limitations, and negatively 
associated with neuroticism and openness. Neuroticism and agreeableness were positively associated with functional limitations, while conscientiousness, extraversion and openness were negatively associated with functional limitations. Composite PSS was positively associated with conscientiousness, neuroticism, extraversion and openness, and negatively associated with neuroticism. Composite PSS was also negatively associated with functional limitations.

\section{Primary Analyses}

After bivariate associations were estimate, age, education, the Big Five and PSS were standardized (mean centered and divided by its standard deviation to transform variables such that the mean was 0 and the SD was 1 ) to make findings easier to interpret. To examine which of the Big Five personality traits predicted functional limitation through the underlying mechanism of PSS, we utilized 5 separate mediation models in PROCESS. Each model included a single Big Five personality trait as the predictor, PSS as the mediator and functional limitations as the outcome. Each model also adjusted for demographics and the other 4 personality traits. The PROCESS program does not give exact p-values for indirect effects. Instead, statistical significance is established with a 95\% confidence interval for the indirect effect that does not cross zero.

Neuroticism. See figure 1 for the mediation effects for neuroticism. There was a significant positive direct effect between neuroticism and functional limitations such that those scoring higher in neuroticism reported more functional limitations. There was a negative association between neuroticism and PSS such that those scoring higher in neuroticism reported less PSS. There was also a significant negative effect of PSS on functional limitations such that those reporting more PSS also reported less functional limitations. Evaluation of the indirect effect revealed that PSS did significantly mediate the neuroticism-functional limitations 
association. Those scoring higher in neuroticism reported less PSS, and those reporting less PSS had greater functional limitations. The total effect for the model, which encompassed the direct effect and the indirect effect, was also significant.

Conscientiousness. See figure 2 for the mediation effects for conscientiousness. There was a significant negative direct effect between conscientiousness and functional limitations, where participants who scored higher in conscientiousness reported less functional limitations. There was a significant positive association between conscientiousness and PSS, where participants who scored higher in conscientiousness reported more PSS. There was also a significant negative effect of PSS on functional limitations such that participants who reported more PSS also reported fewer functional limitations. Based on the evaluation of the indirect effect, PSS did significantly mediate the conscientiousness-functional limitations association. Those scoring higher in conscientiousness reported more PSS, and those reporting more PSS reported fewer functional limitations. Also, the total effect for the model was significant.

Extraversion. See figure 3 for the mediation effects for extraversion. Similar to conscientiousness, there was a significant negative direct effect between extraversion and functional limitations such that participants who scored higher in extraversion reported fewer functional limitations. Additionally, there was a significant positive association between extraversion and PSS where participants who scored higher on extraversion reported more PSS. Consistent with other results, there was also a significant negative effect of PSS on functional limitations. The indirect effect revealed PSS did significantly mediate the association between extraversion and functional limitations. Those who scored higher in extraversion reported more PSS, and those reporting more PSS reported lesser functional limitations. Also, the total effect for the model was significant. 
Agreeableness. See figure 4 for the mediation effects for agreeableness. The total effect for the model was significant. There was a significant positive association between agreeableness and functional limitations such that those who scored higher on agreeableness reporting more functional limitations. There was also a significant positive association between agreeableness and PSS where participants who scored higher on agreeableness reported more PSS. There was also a significant negative effect of PSS on functional limitation such that participants who reported more PSS also reported fewer functional limitations. The evaluation of the indirect effect indicated that PSS was a significant mediator for the agreeableness-functional limitations association. Participants who scored higher on agreeableness reported more PSS, and those who reported more PSS also reported lesser functional limitations. What about total effect?

Openness to experience. See figure 5 for the mediation effects for openness. The total effect for the model was not significant. There was not a significant association between openness and functional limitations, nor openness and PSS. However, PSS did have a significant negative association with functional limitations. This analysis revealed that openness did not have a significant direct association with functional limitations and it was not significantly mediated by PSS.

\section{Exploratory Moderation Analyses with Age}

To further understand the association between personality and functional limitations, exploratory analyses were conducted with age as a moderator based on prior research suggesting differential effects of personality on health at various ages (Shanahan et al., 2012). Moderation analyses were conducted using the Hayes (2012) PROCESS macro, Model 1. The associations for neuroticism, conscientiousness and extraversion and functional limitations were significantly moderated by age. For each significant interaction I also ran the Johnson-Neyman technique to 
test the specific regions the interaction was significant. I also used the Interaction v.1.7 (Soper, 2006-2013) to test the simple slopes for each interaction. Lastly, I plotted each significant interaction along the full continuum of possible personality scores for older adults (1 SD above the mean), middle age adults (average age), and younger adults (1 SD below the mean).

Neuroticism and age. See figure 6 or the age moderation effects for neuroticism. The moderation analysis for the neuroticism and functional limitation association revealed that age was a significant moderator: $F(1,6093)=4.2506, p<.05, R^{2}=.0007$. The Johnson-Neyman statistics was not significant, which indicated that neuroticism interacted with age at all levels of the moderator and there was not a specific transition level of the moderator where the interactions became significant. Simple slopes analysis was significant for each level of the interaction, which indicated that each slope was significantly different from zero. The general pattern suggested the effect of neuroticism on functional limitations became stronger with increasing age.

Conscientiousness and age. See figure 7 for the age moderation effects for conscientiousness. The moderation analysis revealed that age was a significant moderator of the conscientiousness and functional limitations association: $F(1,6093)=8.4349, p<.01, R^{2}=$ .0014. The post-hoc Johnson-Neyman statistic revealed that the interaction was not significant for people 27 years old and younger. Thus, individuals who were 28 years old or older experienced a stronger association between conscientiousness and functional limitations. Simple slopes analysis was significant for each level of the interaction, which indicated that each slope was significantly different from zero. The general pattern suggested the effect of conscientiousness on functional limitations was stronger for older individuals. 
Extraversion and age. See figure 8 for the age moderation effects for extraversion. The moderation analysis for extraversion and functional limitations revealed that age was a significant moderator: $F(1,6093)=6.6584, p=.009, R^{2}=.0099$. The post-hoc Johnson-Neyman statistic indicated that the interaction was not significant for people 27 years old and younger. Therefore, individuals who were 28 years old or older experienced a stronger association between extraversion and functional limitations. Simple slopes analysis was significant for each level of the interaction, which indicated that each slope was significantly different from zero. Based on the general pattern, the effect of extraversion on functional limitations became stronger with increasing age as well.

\section{Discussion}

Numerous studies have verified a link between personality and physical health such as self-rated health (Idler \& Benyamini, 1997), chronic disease (Sutin et al., 2013), functional limitations (Duberstein et al., 2003; Puente et al., 2014; Suchy et al., 2010) and mortality risk (Turiano et al., 2015). This study replicated findings for functional limitations, revealing that higher levels of conscientiousness, agreeableness and extraversion were associated with fewer functional limitations, while higher levels of neuroticism was associated with greater functional limitations (Roy et al., 2016 Suchy et al., 2010). Although prior research demonstrated that higher openness to experience is associated with more optimal functional health (Duberstein et al., 2003; Puente et al., 2014; Suchy et al., 2010), this finding was not replicated in the current study. Most importantly, the current study furthered our understanding of why personality is associated with functional limitations. We found that PSS significantly explained why personality traits are associated with functional health.

\section{Personality and Perceived Social Support}


Personality traits are associated with social behavior, including interactions individuals have with their social network (Asendorpf \& Wilpers, 1998; Silva, Henrie, \& Patrick; Walen \& Lachman, 2000). In the current study, neuroticism was associated with less PSS, while conscientiousness, extraversion and agreeableness were associated with greater PSS. While the research examining this association is limited, there is emerging evidence indicating why personality traits are associated with the PSS people report. For example, individuals scoring higher in neuroticism are often depressed or anxious, which makes them more likely to withdraw from social situations (Bowling, et al., 2005). Therefore, individuals who are higher in neuroticism likely experience less social interaction, including PSS, which can be especially challenging over long periods of time (Smith, Barstead, \& Rubin, 2017). Contrary to neuroticism, individuals higher in conscientiousness or extraversion were less likely to withdraw from their social network even when dealing with depression because of the propensity to uphold responsibility in their relationships (Cukrowicz et al., 2008). The findings indicated that the tendency to be responsible, maintain social interactions with others, and reach out to others increased PSS. Individuals who are higher in conscientiousness, whom are better at selfregulation, are more apt to dealing with the difficulty if a lack of social interaction does occur (Smith et al., 2017). Individuals higher in extraversion are more likely to seek out social situations in general because these situations provided opportunities for extraverted behaviors such as being talkative, lively and friendly (Snyder, 1983). Individuals who are higher in extraversion also tend to have higher positive affect, and individuals with higher positive affect rated their perceived their interactions with others as more enjoyable, comfortable and pleasant compared to individuals with lower positive affect (Berry \& Hansen, 1996). One study looking at satisfaction with friendships indicated greater amount of social interactions could potentially 
raise the overall likelihood of having a larger social network and higher satisfaction with their social network (Wilson et al., 2015). Both extraversion and agreeableness were also linked to providing more supportive interactions in one study (Bowling et al., 2005). Participants higher in extraversion and/or agreeableness provided more non-job and positive work-related social support, thus, were more likely to receive more of those types of support as well. This study emphasized that receiving support was contingent on giving support. While the measure of support differed for PSS because it focused on the job environment, it measured similar aspects to PSS such as emotional support and informational support.

\section{Perceived Social Support and Functional Limitations}

The current study replicated prior work finding that more reported PSS were associated with fewer functional limitations (Lachman \& Agrigoroaei, 2010; Mavandadi et al., 2007). Research has identified that PSS are health protective because they indicate better social integration, less stress, better health behaviors, more recovery from functional limitations and more effective coping methods (Mavandadi et al., 2007). In terms of the social environment and integration, participants with higher PSS experience more emotionally beneficial interactions that allow them to feel cared for and valued, obtain advice and understanding, and have companionship (Mavandadi et al., 2007). These individuals experience better health compared to individuals that experience more stressful relationships or who are socially isolated (Lachman \& Agrigoroaei, 2010). Additionally, people higher in PSS are better able to buffer stress and typically experience a more active, engaged and healthy lifestyle overall. For example, one aspect of PSS, emotional support, was linked to higher physical activity (Seeman et al., 1995). This indicated that PSS could be associated with health behaviors that lessen functional decline throughout the lifespan. If functional declines do occur, PSS can still be beneficial. In one study, 
older adults who had dealt with a stroke and had more PSS experienced faster recovery from functional limitations (Glass, et al., 1993). These researchers indicate that higher PSS may be beneficial for coping, compared to other methods such as denial. Over time this can be beneficial for helping people deal with stress more efficiently. Prolonged stress leads to issues with immune functioning, which lengthens the discomfort and pain one endures (Haufler, Feuerstein \& Huang, 2000). With time, this can lead to greater functional limitations. Moreover, research has indicated that PSS help with promoting less threatening reactions to adverse events in addition to promoting beneficial coping strategies (Cohen, 2004). Perceiving less threat and coping effectively is important for reducing stress, which is linked to greater mortality risk and impaired immune response (Cohen, 2004). Essentially PSS can help provide solutions to stressful situations, reduce stress caused by those situations or distract people from them. Based on existing research PSS appear to be protective against functional limitations, linked to fewer functional limitations and beneficial for recovery from functional limitations (Glass et al., 1993; Lachman \& Agrigoroaei, 2010; Mavandadi et al., 2007; Seeman et al., 1995). However, more research is needed to examine exactly how PSS directly or indirectly impact functional health.

\section{Personality, Perceived Social Support, and Functional Limitations}

Research has linked personality to PSS and PSS to functional limitations, however, there is a lack of research exploring how all three of these variables are connected. This study addresses that gap by providing evidence that personality indirectly predicted functional health via PSS. This is an important extension of this literature because researchers in the field of personality and health have been trying to understand the various mechanisms that can better explain their association. However, there is limited research investigating the roles of social exchanges in this association. Personality is defined by relatively enduring patterns of behavior, 
emotions and beliefs. It can impact how individuals will interact and respond to members of their social network in social exchanges (Caspi et al., 1987; Smith, 2006). For example, individuals higher in conscientiousness are responsible and maintain social contacts even when dealing with stress. The social contact can be useful for coping with stressful situations and individuals higher in conscientiousness tend to be effective at coping (Carver \& Smith, 2008; Cukrowicz et al., 2008). Differing from conscientiousness, neuroticism was the only personality trait linked to less PSS. Individuals who are higher in neuroticism may choose to withdraw from social interactions because of anxiety (Smith et al., 2017). Contrary, extraversion was linked to more PSS and less functional limitations. Individuals higher in extraversion may prefer social interactions and may demonstrate more positive affect and provide PSS. Therefore, these individuals may experience more PSS because reciprocity is predictive of PSS (Bowling et al., 2005; Smith et al., 2017; Snyder, 1983). Similarly, individuals higher in agreeableness also tend to provide more PSS and, therefore, experience more PSS in return (Bowling et al., 2005). Experiencing PSS can be both protective against stressful circumstances and can be beneficial for an individual's physical health by preventing, lessening or helping people recover from functional limitations (Glass et al., 1993; Lachman \& Agrigoroaei, 2010; Mavandadi et al., 2007; Seeman et al., 1995). Individuals higher in personality traits that are associated with higher PSS would likely experience better functional health.

\section{Age Interaction}

Through exploratory analysis, this study found that age was a significant moderator of personality and functional limitations. These findings support researchers emphasizing the importance of investigating age as a moderator of the personality and health association (Shanahan et al., 2012). Age moderated the associations for neuroticism, conscientiousness and 
extraversion in consistent patterns. The moderation effects for conscientiousness, neuroticism and extraversion, and functional limitations were particularly important for older aged individuals. Much of the previous research on personality and functional limitations focused solely on older adults, however, some functional limitations were found for younger and middle aged people as well. Examining younger ages could help researchers understand the people who experience functional limitations earliest and why they were at risk. There are numerous reasons for why this moderation may be more important for older individuals. For example, conscientiousness has been linked to better health behaviors, while neuroticism has been linked to worse health behaviors (Bogg \& Roberts, 2004; Cheng, Weiss \& Siegel, 2015). It takes a long amount of time (depending on the specific behavior in question) for the negative effects of continued health behavior decisions to accumulate to influence overall health (Bogg \& Roberts, 2004). Another explanation may be that the physiological strain that people experience can cause harmful effects with time. Individuals higher in neuroticism experience more stress and anxiety compared to individuals higher in conscientiousness and extraversion. Stress and anxiety have been linked to impaired immune responsiveness, which makes people more prone to pain, discomfort and eventual increased functional limitations (Haufler et al., 2000). Contrary, individuals higher in conscientiousness tend to use coping methods that overcome causes of stress and anxiety such as action-oriented (Carver \& Smith, 2008). This method helps alleviate stress faster, which avoids the consequences of prolonged stress such as impaired immune response. Individuals higher in extraversion experience more positive affect in general and are less impacted by threatening situations (Robinson et al., 2005). There are various potential explanations for why the personality-functional limitations association would be more important as we get older, however, more research is necessary to explore these different avenues. 


\section{Limitations and Future Directions}

The strengths of the current study must be carefully weighed against several qualifications. One key qualification was the strength of the mediation and moderation findings. While these findings were significant for several personality traits, the change in the variance accounted for, or $\mathrm{R}^{2}$ change, was small. As previous researchers have noted, the size of effects provided a better sense of the significance of findings than the p value (Lantz, 2013; Kaplan, Chambers, \& Glasgow, 2014). The large sample used in this study may account for the significant findings instead of the association between the variables. With larger samples there is a risk of inflating p-values and making a Type 1 error. Though these findings are small they may still be worth noting. More research would be needed to determine if there are consistent mediation and moderation associations. If the associations are significant, the information can be utilized to identify people who are most at-risk. Specifically, mediation would help identify how personality is linked to functional limitations, and if it is significant then it may be possible to intervene at the level of the mediator. Through intervention, methods could be developed that would help prevent or delay the onset of functional limitations.

Qualifications related to the sample from this study were also notable. For instance, the MIDUS sample includes participants that are primarily well educated and Caucasian, which limits the generalizability of the findings. Therefore, further research is needed with more academically and ethnically diverse samples.

The measure for personality, PSS, and functional limitations also encompassed potential qualifications. Since the measure of personality used in this study was brief, we are unable to examine facets of personality traits in the current study. Recently, researchers have emphasized the importance of looking at specific facets of personality traits (Quevedo \& Abella, 2011). 
Moreover, this study did not replicate findings for negative association between openness to experience and functional limitations revealed by other researchers (Puente et al., 2014; Suchy et al., 2010). Openness is a broad trait, and the MIDUS measure of personality is very brief and it did not encompass all components of openness like other more inclusive measures. Other studies that found significance used the NEO PI-R, which contains a total of 240 items and, therefore, may be more thorough (Suchy et al., 2010). There were also limitations with the PSS measure because the MIDUS data did not include a measure for appraisals of PSS. PSS are meant to encompass the satisfaction one has with their social network, however, the scales do not always include explicit questions to address satisfaction. Appraisals of PSS assess satisfaction with each of the domains of PSS using direct questions such as "In general, how satisfied are you with the advice and information that you receive?” (Newsom et al., 2005, p.306). Previous research on PSS has detected weak or inconsistent results because interactions meant to be helpful can be unwanted (Newsom et al., 2005). PSS may not be positive interactions if the recipient does not perceive them as helpful; therefore, it is vital to measure the participants' appraisals of the PSS (Newsom et al., 2005). Therefore, future research that incorporates an appraisal scale into the survey would be needed for accurate measurement of PSS. Lastly, the measure of functional limitations only accounted for perceived ability to complete physical tasks rather than actual ability to complete those tasks. Researchers that have studied both perceived functional limitations and actual functional limitations discovered that actual performance-based functional limitations were more valid (Suchy et al., 2010). Participants had a greater risk of overreporting or underreporting functional limitations when self-report measurement was used because of a lack of self-awareness. More valid and reliable measures could be utilized in future research. 
Mediation analyses. Findings revealed that PSS significantly mediated the link between personality and functional limitations, providing some information on why the personality-health link exists. While these findings were significant, it is important to note that they were also small in size, however, that does not mean they were not important. Researchers have commented about guidelines being too restricted, which may lead to researchers missing important associations (Hemphill, 2003) thus this study provides initial evidence of these possible mediated pathways that will need to be replicated in future work. Additionally, this study used crosssectional methods utilizing only Wave 1 MIDUS in the present analyses. This is a concern for mediation analyses because all measures were obtained at a single time making it difficult to determine the directionality of associations. For example, it is not possible to determine if PSS predicted functional limitations or if functional limitations predicted PSS. Moreover, with one wave of data it is not possible to tell if personality and PSS are predictive of changes in functional limitations so further research is needed utilizing multiple waves of data. This is an issue because in this mediation it is expected that personality would have changed PSS and then PSS would alter functional limitations. The change would not be indicated if participants reported the information for all three variables at the same time. With longitudinal research it would be possible to examine the direction of the effects or to determine if there is a bidirectional association between these variables (Williams \& MacKinnon, 2008). Additionally, it is difficult to determine the direction of effects. In this study, personality and PSS were the independent variables, however, one's amount of functional limitations may affect their personality and PSS. The study was primarily a first step into investigating the links between personality, PSS and functional limitations, therefore, much research is still needed to understand the associations between these variables in a causal chain. 
Future Directions. The findings of this study indicate the importance of investigating PSS in the personality and functional limitations link. However, it is a first step to a variety of other potential analyses. For instance, it would be beneficial to explore both PSS and negative social exchanges (NSEs) in future research to understand the mediating ability of social exchanges more completely. People experience more PSS than NSEs, however, NSEs may elicit stronger responses from an individual because they are less common (Rook, Luong, Sorkin, Newsom, \& Krause, 2012). Moreover, there may also be interactions between PSS and NSEs that would be valuable to investigate such that the ratio of PSS to NSEs could have important effects on health outcomes. Similarly, personality traits have been found to interact to predict different outcomes (Turiano, Mroczek, Moynihan \& Chapman, 2014), thus it may be possible that personality traits interact to influence one's social exchanges and functional limitations more strongly than single traits. For example, an individual who is higher in both neuroticism and extraversion may be less socially withdrawn and have more PSS. These individuals may still experience more stressful situations because of their neuroticism, but the benefits of PSS, such as improved coping, may make those situations easier to overcome. Alternatively, the extraversion may drive someone to continue interactions with social network members that are unhealthy and associated with low support and increased stress. Clearly, more research is needed in this area.

This study included age moderation on the personality and functional limitations association, which suggested that the association between personality and functional limitations was stronger in older age. Personality, PSS and functional limitations can change across the lifespan, which may explain this why age would be important to investigate as a moderator. Prior research identified that personality can change throughout the lifespan and at certain developmental periods (Roberts \& Wood, 2006). For example, conscientiousness increases in 
emerging adulthood and midlife, and openness to experience decreases in older adulthood.

Overall people tend to become more socially mature as they age as well meaning they become more confident, warm, responsible and caring, which benefited them in becoming a productive and valuable member of society (maturity principle; Caspi, Roberts and Shiner, 2005; Roberts \& Wood, 2006). The social convoy model also provides reasoning as to why people’s social network changes throughout the lifespan. As people get older their social network narrows and more time is spent with people that are likely to provide PSS (Kahn \& Antonucci, 1980). Lastly, functional limitations and physical health concerns generally are more prevalent as people get older (Seeman et al., 1995). Therefore, further investigation is needed to identify if age moderates the indirect effects between personality, PSS and functional limitations.

\section{Implications}

The findings of this study indicate the importance of investigating the role of PSS and age in the personality and health link. Numerous studies have indicated that personality has a significant association with health, and understanding the reasons behind this association can have many practical uses. First, personality can be used to quickly assess who might be at risk for fewer PSS and also poorer functional health. Such identification could help inform which individuals may need assistance to increase social network functioning and physical health. Secondly, understanding connections between personality, PSS and functional health can inform interventions to promote improving health (Friedman \& Kern, 2014; Idler \& Benyamini, 1997; Sutin et al., 2013; Turiano et al., 2015). It may be possible to tailor existing interventions for increasing PSS or functional health depending on the traits of the participants with the goal of making the interventions more effective. For example, people higher in neuroticism may need a stronger, more thorough intervention than people lower on neuroticism. Another route of 
intervention could be to help people change their personality to potentially improve their social networks and their PSS. For example, interventions aimed at making people more responsible, increasing positive affect and lessening anxiety may lead to greater PSS. Researchers have discovered that personality, particularly neuroticism (e.g., emotional instability), can change using methods such as therapy (Roberts, Luo, Chow \& Su, 2017). Understanding the role of PSS in the personality and health association may inform interventions efforts aimed at improving health throughout the lifespan.

\section{Conclusions}

While studies have investigated personality and PSS or PSS and functional limitations, there was a lack of research looking at the association for all three. This study aimed to understand if PSS significantly mediated the association between personality and functional limitations. There was a significant mediation for most personality traits, and exploratory age moderation revealed that the association between personality and functional health could be stronger in older age. Social aspects of one’s environment can be influenced by one’s personality, which can link to the onset and progression of functional limitations. Understanding the role of social aspects, such as PSS, and age can aid in learning how to prevent functional limitations as people get older. 


\section{References}

Alport, G. W. \& Odbert, H. S. (1936). Trait-names: A psycho-lexical study. Psychological Review Publications, 211, 1-178.

Asendorph, J. B. \& Wilpers, S. (1998). Personality effects on social relationships. Journal of Personality and Social Psychology, 74(6), 1531-1544.

Baer, J., Schreak, M., Althoff, R. R., Rettew, D., Harder, V., Ayer, L., Albaugh, M., Crehan, E., Kuny-Slock, A., \& Hudziak, J. J. (2015). Child temperament, maternal parenting behavior, and child social functioning. Journal of Child and Family Studies, 24, 1152-1162. doi:10.1007/s10826-014-9924-5

Barrera, M. (1986). Distinctions between social support concepts, measures, and models. American Journal of Community Psychology, 14, 413-445. doi:10.1007/BF00922627

Bogg, T. \& Roberts, B. W. (2004). Conscientiousness and health-related behaviors: A metaanalysis of the leading behavioral contributors to mortality. Psychological Bulletin, 130, 887-919. doi:10.1037/0033-2909.130.6.887

Bowling, N. A., Beehr, T. A., \& Swader, W. M. (2005). Giving and receiving social support at work: The roles of personality and reciprocity. Journal of Vocational Behavior, 67, 476498. doi:10.1016/j.jvb.2004.08.004

Carstensen, L. L. (2006). The Influence of a sense of time on human development. Science, 312(5782), 1913-1915. doi:10.1126/science.1127488

Carver, C. S. \& Conner-Smith, J. (2009). Personality and coping. Annual Review of Psychology, 61, 679-704. doi:10.1146/annurev.psych.093008.100352

Caspi, A., Bolger, N. Eckenrode, J. (1987). Linking person and context in the daily stress process. Journal of Personality and Social Psychology, 52, 184-195. 
Caspi, A., Elder, G. H., \& Bem, D. J. (1987). Moving against the world: Life-course patterns of explosive children. Developmental Psychology, 23(2), 308-313.

Cattell, R. B. (1943). The description of personality: Basic traits resolved into clusters. The Journal of Abnormal and Social Psychology, 38(4), 476-506. doi:10.1037/h0054116

Cattell, R. B. (1945). The principal trait clusters for describing personality. Psychological Bulletin, 42, 129-161. doi:10.1037/h0060679

Cheng, C-H. E., Weiss, J. W., \& Siegel, J. M. (2015). Personality traits and health behaviors as predictors of subjective wellbeing among a multiethnic sample of university-attending emerging young adults. International Journal of Wellbeing, 5, 21-43. doi:10.5502/ijw.v5i3.2

Clark, L. A. \& Watson, D. (2008). In O. P. John, R. W. Robins, \& L. A. Pervin (Eds.), Handbook of Personality: Theory and Research (3rd ed., pp. 265-286). New York, NY: Guilford Press.

Cohen, S. (2004). Social relationships and health. American Psychologist, 59(4), 676-684. doi:10.1037/0003-066X.59.8.676

Duberstein, Sörensen, S., Lyness, J. M., King, D. A., Conwell, Y., Seidliz, L., \& Caine, E. D. (2003). Personality is associated with perceived health and functional status in older primary care patients. Psychology and Aging, 18, 25-37. doi:10.1037/0882-7974.18.1.25

Felsten, G. (2002). Minor stressors and depressed mood: Reactivity is more strongly correlated than total stress. Stress and Health, 18, 75-81. doi:10.1002/smi.925

Friedman, H. S., Kern, M. L., \& Reynolds, C. A. (2010). Personality and health, subjective wellbeing, and longevity. Journal of Personality, 78, 180-216. doi:10.1111/j.1467- 
6494.2009.00613.x

Friedman, H. W., Tucker, J. S., Tominson-Keasey, C., Schwartz, J. E., Wingard, D. L. \& Criqui, M. H. (1993). Does childhood personality predict longevity? Journal of Personality and Social Psychology, 65(1), 176-185.

Glass, T. A., Matchar, D. B., Belyea, M., \& Feussner, J. R. (1993). Impact of social support on outcome in first stroke. Stroke, 24, 64-70. doi:10.1161/01.STR.24.1.64

Goldberg, L. R. (1981). Language and individual differences: The search for universals in personality lexicons. In L. Wheeler (Ed.), Review of personality and social psychology ( ${ }^{\text {nd }}$ ed., pp. 141-165). Beverly Hills, CA: Sage.

Goldberg, L. R. (1990). An alternative “description of personality”: The Big Five factor structure. Journal of Personality and Social Psychology, 59(6), 1216-1229.

Goldberg, L. R., Sweeney, D., Merenda, P. F., \& Hughes, J. E. J. (1998). Demographic variables and personality: The effects of gender, age, education, and ethnic/racial status on selfdescriptions of personality attributes. Personality and Individual Differences, 24, 393403.

Greenglass, E., Fiksenbaum, L. \& Eaton, J. (2006). The relationship between coping, social support, functional disability and depression in the elderly. Anxiety, Stress, and Coping, 19(1), 15-31. doi:10.1080/14659890500436430

Haufler, A. J., Feuerstein, M., Huang, G. D. (2000). Job stress, upper extremity pain and functional limitations in symptomatic computer users. American Journal of Industrial Medicine, 38, 507-515. 
Hampson, S. E., \& Friedman, H. S. (2008). Personality and health. In O. P. John, R. W. Robins, \& L. A. Pervin (Eds.), Handbook of Personality: Theory and Research (3rd ed., pp. 770794). New York, NY: Guilford Press.

Hayes, A. F. (2009). Beyond Baron and Kenny: Statistical mediation analyses in the new millennium. Communication Monographs, 76, 408-420.

doi:10.1080/03637750903310360

Hayes, A. F. (2012). PROCESS: A versatile computational tool for observed variable mediation, moderation, and conditional process modeling [White paper]. Retrieved from http://www.afhayes.com/ public/process2012.pdf

Hayes, A. F. (2013). Introduction to mediation, moderation, and conditional process analysis: A regression-based approach. New York, NY: Guilford Publications, Inc.

Heaven, P. C. L., Smith, L., Prabhakar, S. M., Abraham, J., \& Mete, M. E. (2006). Personality and conflict communication patterns in cohabiting couples. Journal of Research in Personality, 20, 829-840. doi:10.1016/j.jrp.2005.09.012

Heinze, J. E., Kruger, D. J., Reischl, T. M., Cupal, S., \& Zimmerman, M. A. (2015). Relationships among disease, social support and perceived health: A lifespan approach. American Journal of Community Psychology, 56, 268-279. doi:10.1007/s10464-0159758-3

Henningsson S, Baghaei F, Rosmond R, Holm G, Anckarsäter H, et al. (2008) Association between serum levels of C-reactive protein and personality traits in women. Behavioral and Brain Functions, 4(16), 1-8. doi:10.1186/1744-9081-4-16

Hill, J., Fillit, H., Thomas, S.K., Chang, S. (2006). Functional impairment, healthcare costs and the prevalence of institutionalization in patients with Alzheimer's disease 
and other dementias. Pharmacoeconomics, 24, 265-280.

Hintsanen, M., Alatupa, S., Pullmann, H., Hinrstio-Snellman, P., \& KeltikangasJarvinen, L. (2010). Associations of self-esteem and temperament traits to self- and teacher-reported social status among classmates. Scanavian Journal of Psychology, 51, 488-494. doi:10.1111/j.1467-9450-2010.00820.x

Ibrahim, N., Teo, S. S. L., Din, N. C., Gafor, A. H. A., \& Ismail. (2015). The role of personality and social support in health-related quality of life in chronic kidney disease patients. PLoS ONE, 10(7), 1-11. doi:10.1371/journal.pone.0129015

Idler, E. L. \& Benyamini, Y. (1997). Self-rated health and mortality: A review of twenty-seven community studies. Journal of Health and Social Behavior, 38(1), 21-37.

Ingersoll-Dayton, B., Morgan, D. \& Antonucci, T. (1997). The effects of positive and negative social exchanges on aging adults. Journal of Gerontology, 52B(4), S190-S199.

John, O. P., \& Srivastava, S. (1999). The Big-Five trait taxonomy: History, measurement, and theoretical perspectives. In L. A. Pervin \& O. P. John (Eds.), Handbook of Personality: Theory and Research (Vol. 2, pp. 102-138). New York: Guilford Press.

Jokela, M., Batty, G. D., Nyberg, S. T., Viranen, M., Nabi, H., Singh-Manoux, \& Kivimaki, M. (2013). American Journal of Epidemiology, 178(5), 667-675. doi:10.1093/aje/kwt170

Jonassaint, C. R., Boyle, S. H., Kuhn, C. M., Siegler, I. C., Copeland, W. E. \& Williams, R. (2010). Personality and inflammation: The protective effect of openness to experience. Ethnicity and Disease, 20, 11-14.

Kahn R. L., \& Antonucci T. C. (1980). Convoys over the life course: Attachment, roles, and social support. In Baltes P. B., Brim O. (Eds.), Life-span development and behavior (Vol. 3, pp. 254-283). New York: Academic Press. 
Kaplan, R. M., Chambers, D. A., \& Glasgow, R. E. (2014). Bid data and large sample size: A cautionary note on the potential for bias. Clinical and Translational Science, 7, 342-346. doi:10.1111/cts.12178

Katz, S., Ford, A.B., Moskowitz, R.W., et al. (1963). Studies of illness in the aged. The Index of ADL: a standardized measure of biological and psychosocial function. Journal of the American Medical Association, 185, 914-919.

Kern, M. L., Della Porta, S. S., \& Friedman, H. S. (2013). Lifelong pathways to longevity: Personality, relationships, flourishing, and health. Journal of Personality, 82, 472484. doi:10.1111/jopy.12062

Krueger, R. F., South, S. Johnson, W. \& Iacono, W. (2008). The heritability of personality is not always 50\%: Gene-environment interactions and correlations between personality and parenting. Journal of Personality, 76(6), 1485-1521. doi:10.1111/j.14676494.2008.00529.x

Lachman, M. E. \& Agrigoroaei, S. (2010). Promoting functional health in middle and old age: Long-term protective effects of control beliefs, social support, and physical exercise. PLoS ONE, 5(10), 1-9. doi: 10.1371/journal.pone.0013297

Lantz, B. (2013). The large sample fallacy. Scandinavian Journal of Caring Sciences, 27, 487492. doi:10.1111/j.1471-6712.2012.01052.x

Lopes, P. N., Salovey, P., \& Straus, R. (2003). Emotional intelligence, personality, and the perceived quality of social relationships. Personality and Individual Differences, 35, 641658.

Magee, C. A., Heaven, P. C. L., \& Miller, L. M. (2013). Personality change predicts selfreported mental and physical health. Journal of Personality, 81, 324-334. 
Mavandadi, S., Rook, K. S., \& Newsom, J. T. (2007). Positive and negative social exchanges and disability in later life: An investigation of trajectories of change. Journal of Gerontology: Social Sciences, 62B(6), S361-S370.

McCrae, R. R. \& Costa, P. T. (1987). Validation of the Five-Factor model of personality across instruments and observers. Journal of Personality and Social Psychology, 52(1), 81-90.

McElwain, N. L., Ogolsky, B. G., Engle, J. M., Holland, A. S., \& Mitchell, E. T. (2016). Child-child similarity on attachment and temperament as predictors of positive interaction during acquaintanceship at age 3. Developmental Psychology, 52(9), 13941408. doi:10.1037/dex0000190

Morack, J. Infurna, F. J., Ram, N., \& Gerstorf, D. (2013). Trajectories and personality correlates of change in perceptions of physical and mental health across adulthood and old age. International Journal of Behavioral Development, 37(6), 475-484. doi:

\subsection{7/0165025413492605}

Mund, M. \& Neyer, F. J. (2014). Treating personality-relationships transactions with respect: Narrow facets, advanced models, and extended time frames. Journal of Personality and Social Psychology, 107(2), 352-368. http://dx.doi.org/10.1037/a0036719

Okun, M. A., \& Keith, V. M. (1998). Effects of positive and negative social exchanges with various sources on depressive symptoms in younger and older adults. Journal of Gerontology: Psychological Sciences, 53B, P4-P20.

Pennenix, B. W. H., van Tilburg, T., Kriegsman, D. M. W., Deeg, D. J. H., Baeke, A. J. P., \& van Eijk, J. T. M. (1997). Effects of social support and personal coping resources on mortality in older age: The Longitudinal Aging Study Amsterdam. American Journal of Epidemiology, 146(6), 210-519. 
Pereira H, Tomaz C, Cavaco J, \& Tavares-Ratado, P. (2014). Personality and levels of cholesterol and glucose. Journal of Nutrition and Food Sciences, 4. 1-5. doi:10.4172/2155-9600.1000291

Puente, A. N., Lindbergh, C. A., \& Miller, L. S. (2014). Personality's association with IADLs in community dwelling older adults. International Journal of Geriatric Psychiatry, 30, 950956. doi: 10.1002/gps.4243

Quevedo, R. J. M., \& Abella, M. C. (2011). Well-being and personality: Facet-level analyses. Personality and Individual Differences, 50, 206-2011. doi: 10.1016/j.paid.2010.09.030

Righetti, F., Kumashiro, M., \& Campbell, S. B. (2014). Goal difficulty and openness to interpersonal goal support. Personality and Social Psychology Bulletin, 40, 11071118. doi:10.1177/0146167214535954

Roberts, B. W., Luo, J., Briley, D. A., Chow, P. I., Su, R., \& Hill, P. L. (2017, January 5). A systematic review of personality trait change through intervention. Psychological Bulletin. Advance online publication. http://dx.doi.org/10.1037/bul0000088

Robinson, M. D., Meier, B. P., \& Vargas, P. T. (2005). Extraversion, threat categorizations, and negative affect: a reactions time approach to avoidance motivation. Journal of Personality, 73, 1397-1436. doi: 10.1111/j.1467-6494.2005.00353.x

Rook, K. S. (2010). Reactions to spousal control when patients and spouses differ in their commitment to the management of diabetes. Gerontologist, 50, 118-119.

Rook, K. S., Luong, G., Sorkin, D. H., Newsom, J. T., \& Krause, N. (2012). Ambivalent and problematic social ties: Impliations for psychological health, functional health, and interpersonal coping. Psychological Aging, 27, 1-24. doi:10.1037/a0029246

Roy, S., Ficarro, S., Duberstein, P., Chapman, B. P., Dubovky, S., Parosky, M., Szigeti, K., \& 
Benedict, R. H. B. (2016). Executive function and personality predict instrumental activities of daily living in Alzheimer disease. American Journal of Geriatrics, 24(11), 1074-1083. http://dx.doi.org/10.1016/j.jagp.2016.06.014

Seeman, T.E., Berkman, L.F., Charpentier, P.A., Blazer, D.G., Albert, M.S., \& Tinetti, M. E. (1995). Behavioral and psychosocial predictors of physical performance: MacArthur Studies of Successful Aging. Journal of Gerontology: Series A: Biological Sciences and Medical Sciences, 50A, M177-M183. https://doi-org.www.libproxy.wvu.edu/10.1093/gerona/50A.4.M177

Shanahan, M. J., Hill. P. L., Roberts, B. W., Eccles, J. \& Friedman, H. S. (2012). Conscientiousness, health and aging: The life course personality model. Developmental Psycology. 50, 1407-1425. doi:10.1037/a0031130

Silva, N. M., Henrie, J. A., \& Patrick, J. H. (2016). Personality, negative social exchanges, and physical health among bereaved adults. Health Psychology Open, 3, 1-14. doi: $10.1177 / 2055102916637877$

Smith, T. W. (2006). Personality as risk and reliance in physical health. Association for Psychological Science, 15(5), 227-231.

Smith, K .A., Barstead, M. G., \& Rubin, K. H. (2017). Neuroticism and conscientiousness as moderators of the relation between social withdrawal and internalizing problems in adolescence. Journal of Youth and Adolescence, 46, 772-786. https://doiorg.www.libproxy.wvu.edu/10.1007/s10964-016-0594-z

Snyder, M. (1983). The individuals of individuals on situations: Implications for understanding the links between personality and social behavior. Journal of Personality, 51, 497-516.

Suchy, Y., Williams, P. G., Kraybill, M. L., Franchow, E. \& Butner, J. (2010). Instrumental 
activities of daily living among community-dwelling older adults: personality associations with self-report, performance, and awareness of functional difficulties. Journal of Gerontology: Psychological Sciences, 65B(5), 542-550. doi:10.1093/geronb/gbq037

Sutin, A. R., Terracciano, A., Deiana, B., Uda, M., Schlessinger, D., Lakatta, E. G., \& Costa, P. T. (2010). Cholesterol, triglycerides, and the Five-Factor Model of personality. Biological Psychology, 84(2), 186-191. http://doi.org/10.1016/j.biopsycho.2010.01.012

Sutin, A.R., Terracciano, A., Deiana, B., Naitza, S., Ferrucci, L., Uda, M., Schlessinger, D. \& Costa, P.T. (2010) High neuroticism and low conscientiousness are associated with interleukin-6. Psychological Medicine, 40(9), 1485-1493. doi: 10.1017/S0033291709992029.

Sutin, A. R., Zonderman, A. B., Ferrucci, L. \& Terraccino, A. (2013). Personality traits and chronic disease: Implications for adult personality development. Journal of Gerontology, Series B: Psychological Sciences and Socal Sciences, 68(6), 912-920. doi:10.1093/geronb/gbt036

Turiano, N. A., Chapman, B. P., Gruenewald, T. L., \& Mroczek, D. K. (2013). Personality and the leading behavioral contributors of mortality. Health Psychology, 34, 51-60.

Turiano, N. A., Mroczek, D. K., Moynihan, J., \& Chapman, B. P. (2014). Big 5 personality traits and Interleukin-6: Evidence for "healthy neuroticism” in a U.S. population sample. Brain, Behavior, and Immunity, 28, 83-89. doi:10.1016/j.bbi.2012.10.020

Turiano, N. A., Pitzer, L., Armour, C., Karlamangla, A. Ryff, C. D. \& Mroczek, D. K. (2011). Personality trait level and change as predictors of health outcomes: Findings from a national study of Americans (MIDUS). The Journals of Gerontology, Series B: 
Psychological Sciences and Social Sciences, 67B, 1-9.

doi: 10.1093/geronb/gbr072

Walen, H. R. \& Lachman, M. E. (2000). Social support and strain from partner, family and friends: Costs and benefits for men and women in adulthood. Journal of Social and Personal Relationships, 17(1), 5-30.

Ware, J. E. \& Sherborne, C. D. (1992). The MOS 36-item short-form health survey (SF-36): Conceptual framework and item selection. Medical Care, 30(6), 473-483.

Weiss, A. Costa, P. T. (2005). Domain and facet personality predictors of all-cause mortality among Medicare patients ages 65 to 100. Psychosomatic Medicine, 67, 724-733. doi: 0033-3174/05/6705-0724

Williams, J., \& MacKinnon, D. P. (2008). Resampling and distribution of the product methods for testing indirect effects in complex models. Structural Equation Modeling, 15, 23-51. doi:10.1080/10705510701758166

Wilson, R. E., Harris, K., Vazire, S. (2015). Personality and friendship satisfaction in daily life: Do everyday social interactions account for the individual differences in friendship satisfaction? European Journal of Personality, 29, 173-186. doi:10.1002/per.1996

Windsor, T. D., Gerstorf, D. Pearson, E. Ryan, L. H. \& Anstey, K. J. (2014). Positive and negative social exchanges and cognitive aging in young-old adults: Differential associations across family, friend, and spouse domains. Psychology and Aging, 29(1), 2843. doi10.1037/a0035256

Zimmer, Z., \& House, J. S. Education, income, and functional limitations transitions among American adults: Contrasting onset and progression. International Journal of Epidemiology, 32, 1089-1097. doi:10.1093/ije/dyg254 
Table 1

Bivariate Correlations $(n=6,095)$

\begin{tabular}{|c|c|c|c|c|c|c|c|c|c|c|c|c|}
\hline & $M(S D)$ or $\%$ & 1 & 2 & 3 & 4 & 5 & 6 & 7 & 8 & 9 & 10 & 11 \\
\hline 1. Age & $46.81(12.88)$ & - & & & & & & & & & & \\
\hline 2. Race & 9.13 & $-.10 * * *$ & - & & & & & & & & & \\
\hline 3. Gender & 47.49 & -.01 & $-.03 *$ & - & & & & & & & & \\
\hline 4. Marital & 31.87 & $-.05 * * *$ & $.11^{* * *}$ & $-.11^{* * *}$ & - & & & & & & & \\
\hline 5. Education & $6.87(2.47)$ & $-.11 * * *$ & $-.04 * *$ & $.10 * * *$ & -.00 & - & & & & & & \\
\hline 6. Agreeableness & $3.49(.49)$ & $.08 * * *$ & $.03 *$ & $-.27 * * *$ & $.03 * *$ & $-.09 * * *$ & - & & & & & \\
\hline 7. Extraversion & $3.20(.56)$ & -.01 & $.04 * *$ & $-.07 * * *$ & -.01 & -.02 & $.53 * * *$ & - & & & & \\
\hline 8. Neuroticism & $2.24(.66)$ & $-.14^{* * *}$ & -.01 & $-.10 * * *$ & $.06^{* * *}$ & $-.10 * * *$ & $-.05 * * *$ & $-.16^{* * *}$ & - & & & \\
\hline 9. Conscientiousness & $3.42(.44)$ & $.03 *$ & -.02 & $-.11 * * *$ & $-.05 * * *$ & $.10^{* * *}$ & $.29 * * *$ & $.27 * * *$ & $-.20 * * *$ & - & & \\
\hline 10. Openness & $3.02(.53)$ & $-.07 * * *$ & $.06 * * *$ & $.07 * * *$ & $.08 * * *$ & $.21^{* * *}$ & $.35 * * *$ & $.51 * * *$ & $-.17 * * *$ & $.27 * * *$ & - & \\
\hline 11. PSS & $3.59(.57)$ & $.08 * * *$ & $-.06 * * *$ & $-.10 * * *$ & $-.12 * * *$ & $.04 * * *$ & $.28 * * *$ & $.31^{* * *}$ & $-.22 * * *$ & $.22 * * *$ & $.18 * * *$ & - \\
\hline 12. Functional & 1.47 (.68) & $.28 * * *$ & $.04 * * *$ & $-.12 * * *$ & $.08 * * *$ & $-.21 * * *$ & $.05 * * *$ & $-.09 * * *$ & $.13^{* * *}$ & $-.12 * * *$ & $-.10 * * *$ & $-.11^{* * *}$ \\
\hline
\end{tabular}

Limitations 


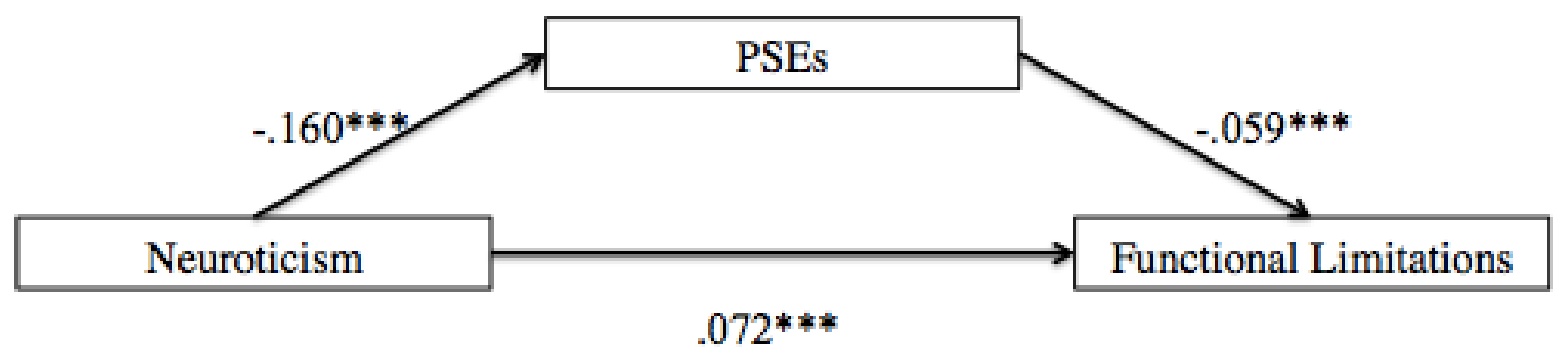

Total Effect: $b=.081 * * *$

Indirect Effect: $b=.014,95 \% \mathrm{CI}[.0091-.0203]$

${ }^{*} p<.05,{ }^{* *} p<.01,{ }^{* * *} p<.001$

Figure 1. The indirect effect of PSS on the relation between neuroticism and functional limitations. 


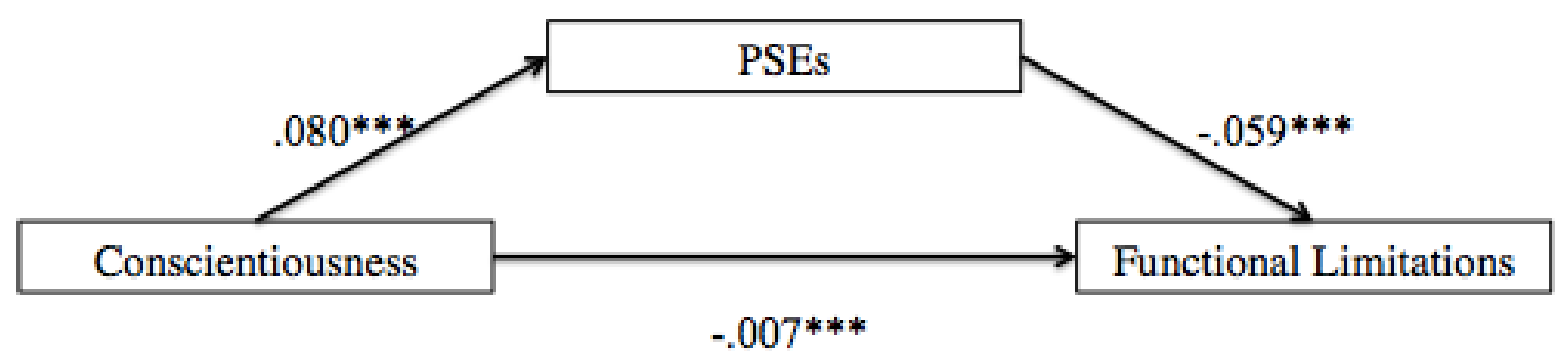

Total Effect: $b=-.065^{* * *}$

Indirect Effect: $b=-.005,95 \% \mathrm{CI}[-.0106--.0041]$

${ }^{*} p<.05,{ }^{* *} p<.01,{ }^{* * *} p<.001$

Figure 2. The indirect effect of PSS on the relation between conscientiousness and functional limitations. 


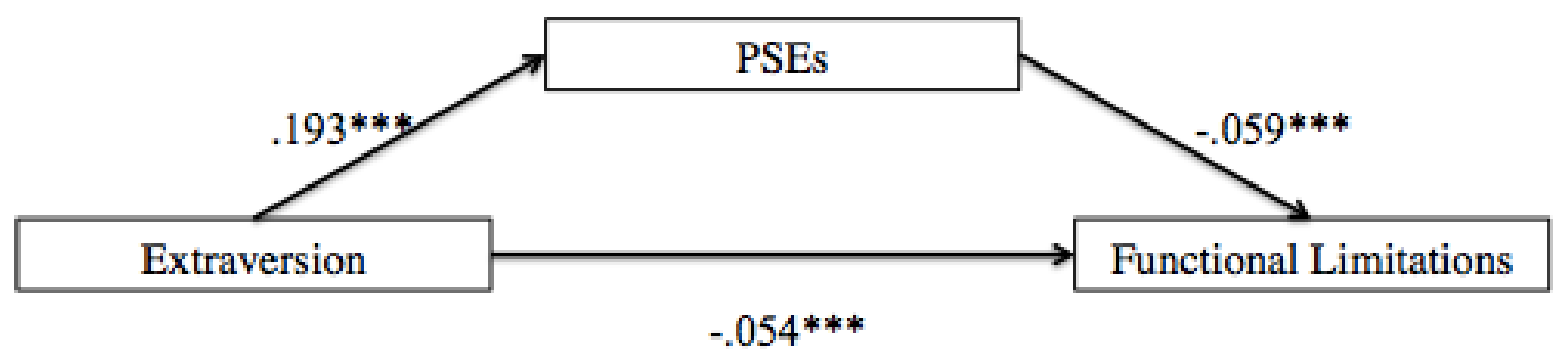

Total Effect: $b=-.065^{* * *}$

Indirect Effect: $b=-.014,95 \% \mathrm{CI}[-.0199--.0093]$

${ }^{*} p<.05,{ }^{* *} p<.01, * * * p .001$

Figure 3. The indirect effect of PSS on the relation between extraversion and functional limitations. 


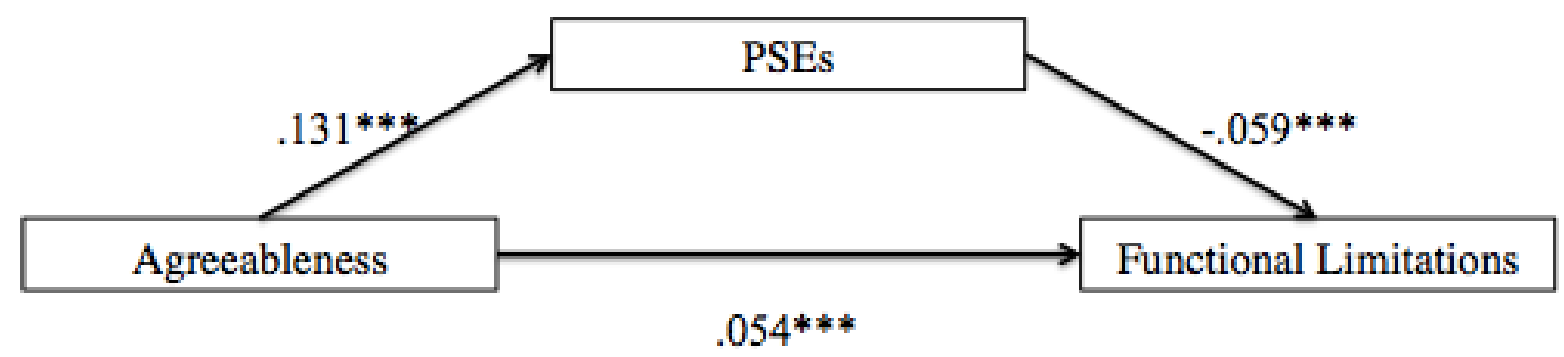

Total Effect: $b=.046 * * *$

Indirect Effect: $b=-.010,95 \% \mathrm{CI}[-.0145--.0062]$

${ }^{*} p<.05,{ }^{* *} p<.01,{ }^{* * *} p<.001$

Figure 4. The indirect effect of PSS on the relation between agreeableness and functional limitations. 


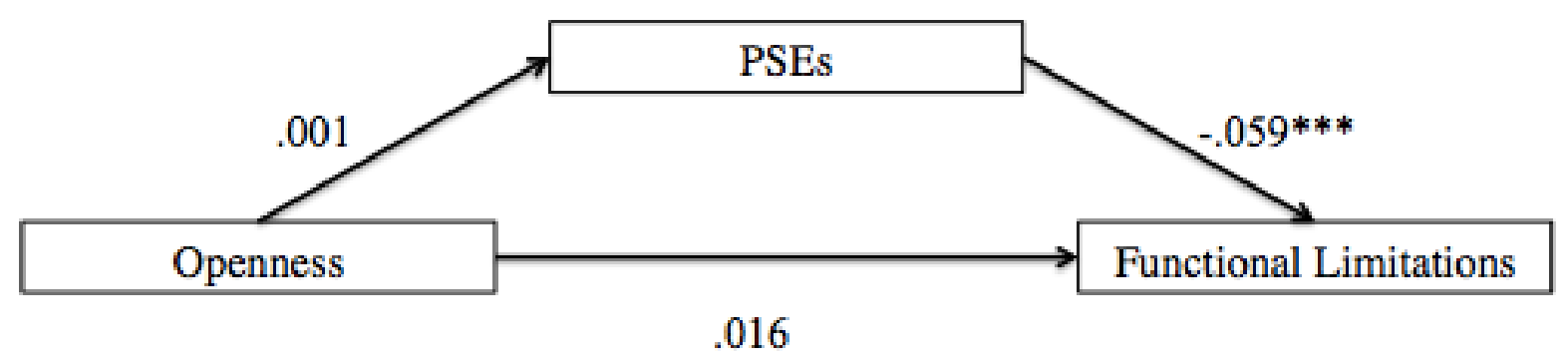

Total Effect: $b=.016$

Indirect Effect: $b=-.000,95 \% \mathrm{CI}[-.0025-.0022]$

${ }^{*} p<.05,{ }^{* *} p<.01,{ }^{* * *} p<.001$

Figure 5. There was no significant indirect effect of PSS on the relation between openness and functional limitations. 


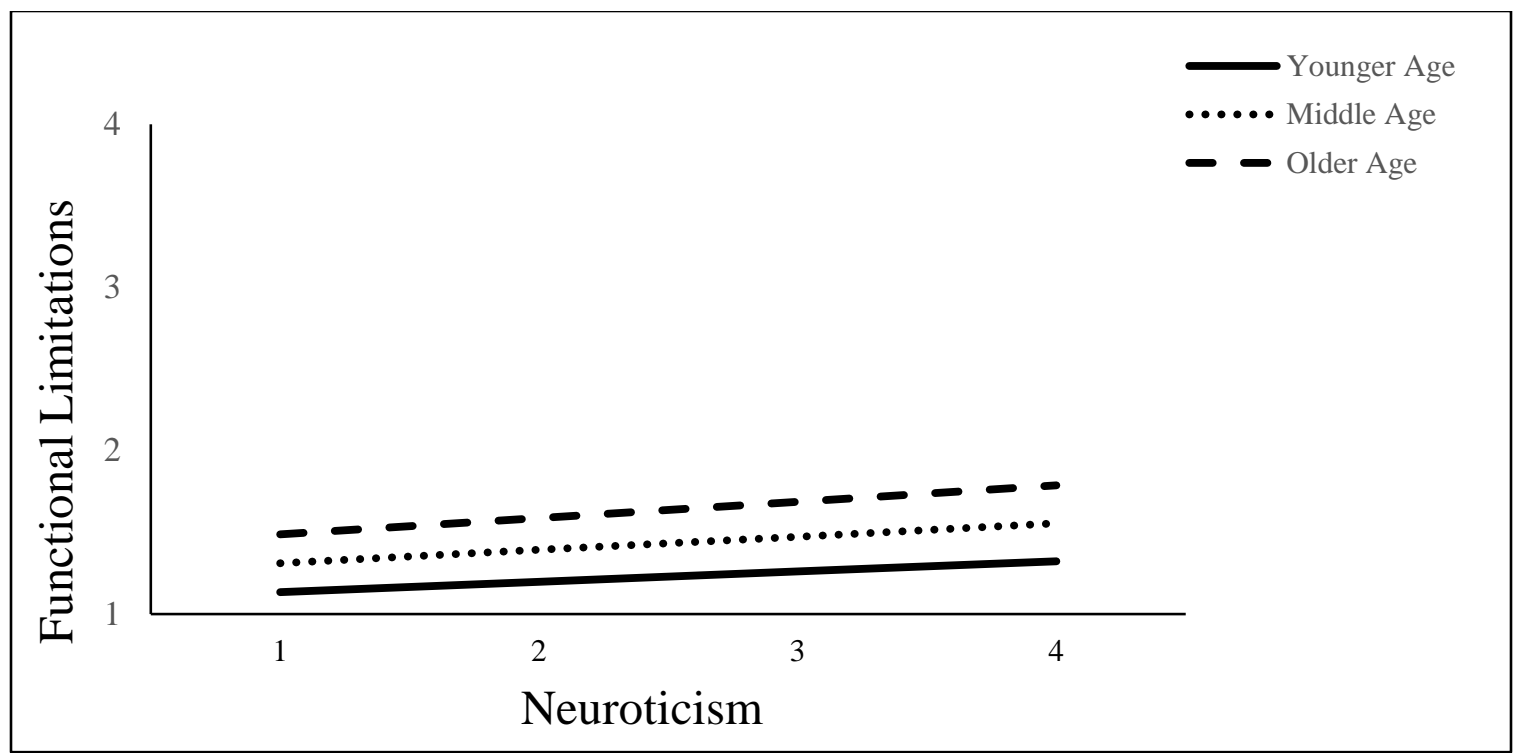

Figure 6. The moderation effect of age on the neuroticism and functional limitations association. Simple slopes test: older age $(t=11.15 ; p<.001)$; middle age $(t=9.81 ; p<.001)$; younger age $(t$ $=6.96 ; p<.001)$. 


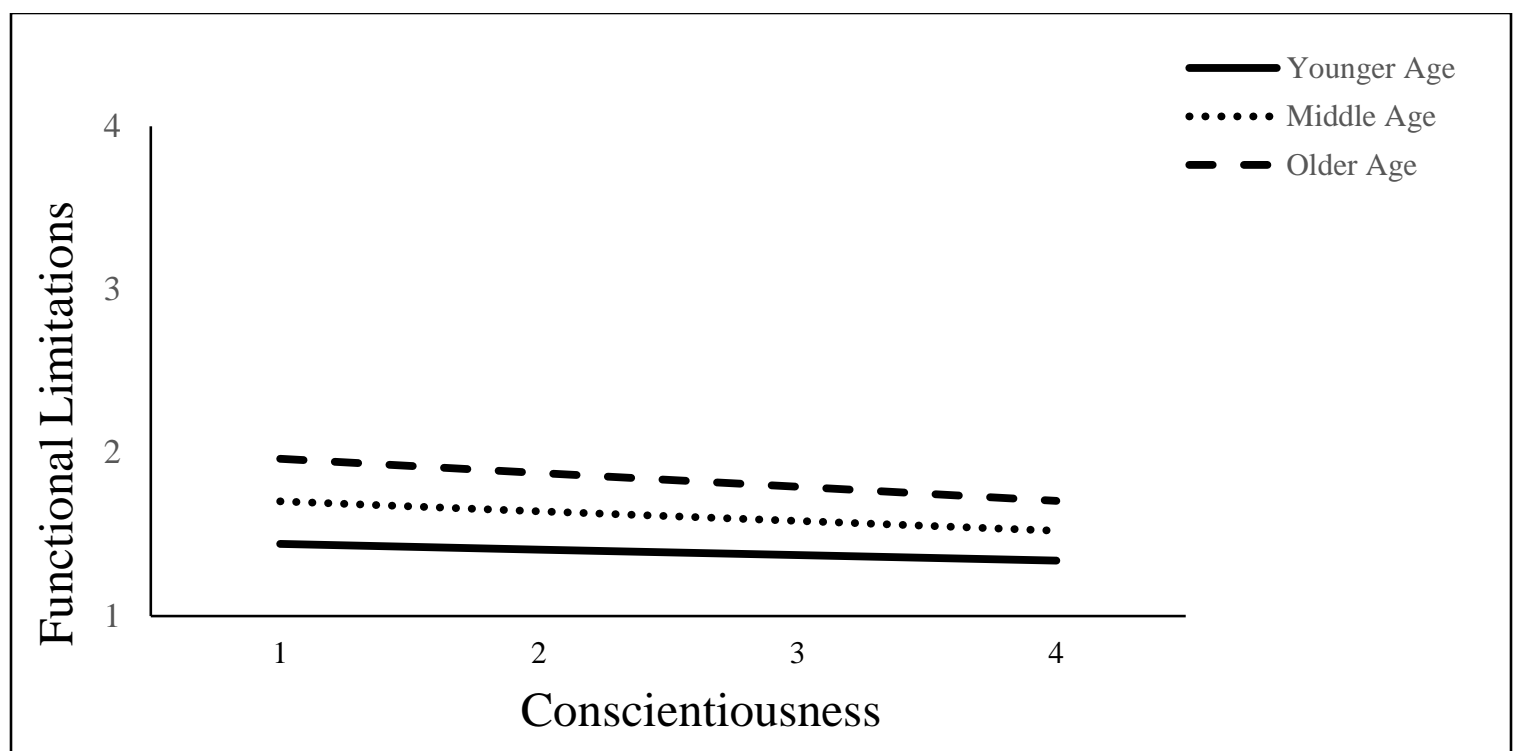

Figure 7. The moderation effect of age on the conscientiousness and functional limitations association. Simple slopes test: older age $(t=-4.51 ; p<.001)$; middle age $(t=-7.51 ; p<.001)$; younger age $(t=-2.27 ; p<.05)$. 


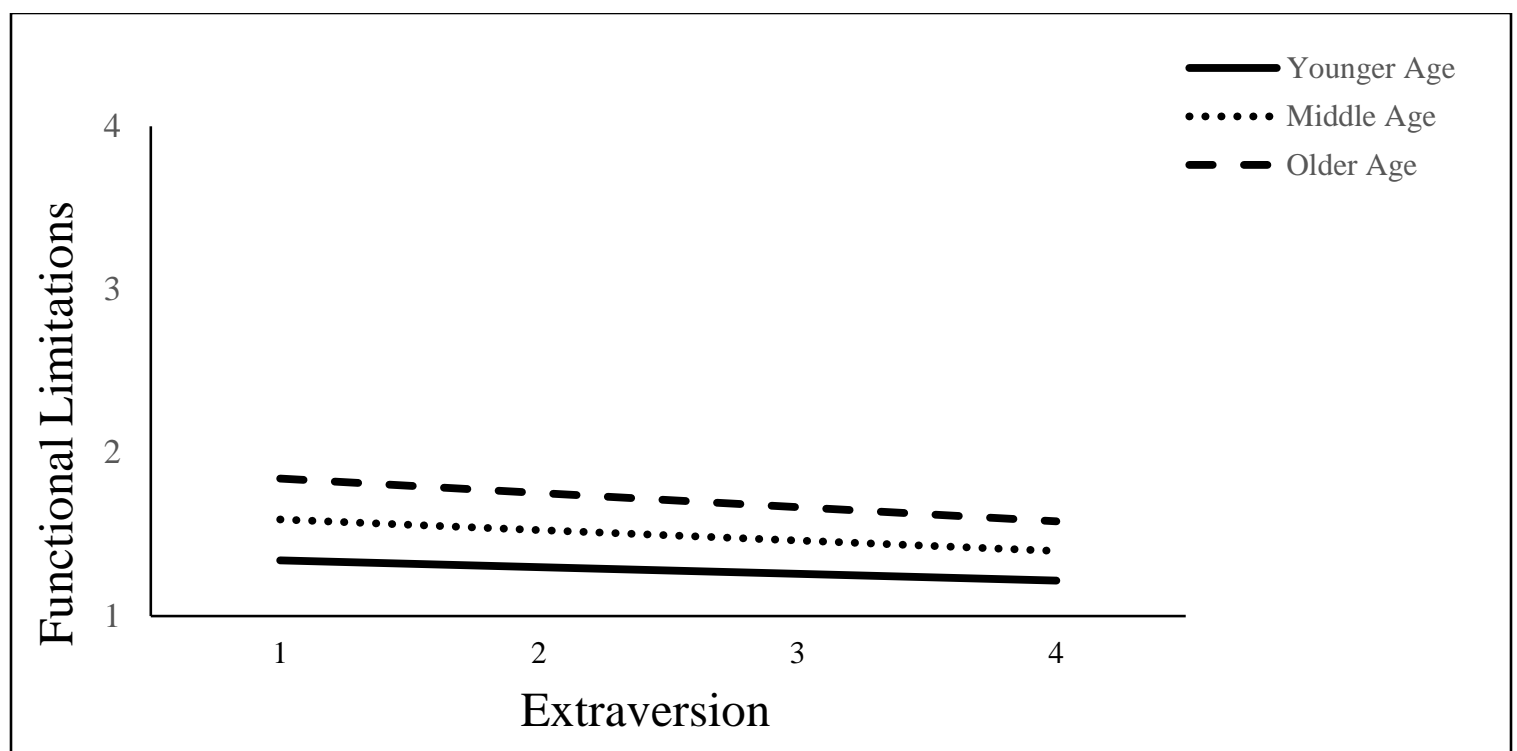

Figure 8. The moderation effect of age on the extraversion and functional limitations association.

Simple slopes test: older age $(t=-4.16 ; p<.001)$; middle age $(t=-6.23 ; p<.001)$; younger age $(t=-2.22 ; p<.05)$ 
Appendix A: Demographics

1. Respondents age

2. Gender of respondent

1. Female

2. Male

3. What is the highest grade of school or year of college you completed?

1. No school/Some grade school

2. Eighth grade/Junior high school

3. Some high school

4. G.E.D

5. Graduated from high school

6. One to two years of college, no degree yet

7. Three or more years of college, no degree yet

8. Graduated two-year college, vocational school, or associates degree

9. Graduated four- or five-year college or Bachelor's degree

10. Some graduate school

11. Master's degree

12. Professional degree (Ph.D., Ed.D., M.D., D.D.S., L.L.B., L.L.D., J.D., or other professional degree).

4. Are you married, separated, divorced, widowed, or never married?

1. Married

2. Separated

3. Divorced

4. Widowed

5. Never married

5. What race do you consider yourself to be?

1. White

2. Black and/or African American

3. Native American or Aleutian Islander/Eskimo

4. Asian or Pacific Islander

5. Other

6. Multiracial 
Appendix B: Midlife Development Inventory Personality Scale

\begin{tabular}{lllll}
\hline & Not at all & A little & Some & A lot \\
\hline Please indicate how well each of the following & & & & \\
describes you. & & & & \\
\hline 1. Outgoing & 1 & 2 & 3 & 4 \\
2. Helpful & 1 & 2 & 3 & 4 \\
3. Moody & 1 & 2 & 3 & 4 \\
4. Organized & 1 & 2 & 3 & 4 \\
5. Friendly & 1 & 2 & 3 & 4 \\
6. Warm & 1 & 2 & 3 & 4 \\
7. Worrying & 1 & 2 & 3 & 4 \\
8. Responsible & 1 & 2 & 3 & 4 \\
9. Lively & 1 & 2 & 3 & 4 \\
10. Caring & 1 & 2 & 3 & 4 \\
11. Nervous & 1 & 2 & 3 & 4 \\
12. Creative & 1 & 2 & 3 & 4 \\
13. Hardworking & 1 & 2 & 3 & 4 \\
14. Imaginative & 1 & 2 & 3 & 4 \\
15. Softhearted & 1 & 2 & 3 & 4 \\
16. Calm & 1 & 2 & 3 & 4 \\
17. Intelligent & 1 & 2 & 3 & 4 \\
18. Curious & 1 & 2 & 3 & 4 \\
19. Active & 1 & 2 & 3 & 4 \\
20. Careless & 1 & 2 & 3 & 4 \\
21. Broad-minded & 1 & 2 & 3 & 4 \\
22. Sympathetic & 1 & 2 & 3 & 4 \\
23. Talkative & 1 & 2 & 3 & 4 \\
24. Sophisticated & 1 & 2 & 3 & 4 \\
25. Adventurous & 2 & 3 & 4 \\
\hline Note. Measurefrom Lachman & & & & \\
\end{tabular}

Note. Measure from Lachman and Weaver (1997). 


\section{Appendix C: Perceived Social Support Scale}

\begin{tabular}{lcccc}
\hline Family & Never & Rarely & Sometimes & Often \\
\hline $\begin{array}{l}\text { 1. Not including your spouse or partner, how much } \\
\text { do members of your family really care about you? }\end{array}$ & 1 & 2 & 3 & 4 \\
2. How much do they understand the way you feel & 1 & 2 & 3 & 4 \\
about things? \\
$\begin{array}{l}\text { 3. How much can you rely on them for help if you } \\
\text { have a serious problem? }\end{array}$ \\
$\begin{array}{l}\text { 4. How much can you open up to them if you need to } \\
\text { talk about your worries? }\end{array}$
\end{tabular}

\begin{tabular}{|c|c|c|c|c|}
\hline Spouse/Partner Perceived Social Support & & & & \\
\hline $\begin{array}{l}\text { 1. How much does your spouse or partner really care } \\
\text { about you? }\end{array}$ & 1 & 2 & 3 & 4 \\
\hline $\begin{array}{l}\text { 2. How much does he or she understand the way you } \\
\text { feel about things? }\end{array}$ & 1 & 2 & 3 & 4 \\
\hline 3. How much does he or she appreciate you? & 1 & 2 & 3 & 4 \\
\hline $\begin{array}{l}\text { 4. How much do you rely on him or her for help if } \\
\text { you have a serious problem? }\end{array}$ & 1 & 2 & 3 & 4 \\
\hline $\begin{array}{l}\text { 5. How much can you open up to him or her if you } \\
\text { need to talk about your worries? }\end{array}$ & 1 & 2 & 3 & 4 \\
\hline $\begin{array}{l}\text { 6. How much can you relax and be yourself around } \\
\text { him or her? }\end{array}$ & 1 & 2 & 3 & 4 \\
\hline Friend Perceived Social Support & & & & \\
\hline 1. How much do your friends really care about you? & 1 & 2 & 3 & 4 \\
\hline $\begin{array}{l}\text { 2. How much do they understand the way you feel } \\
\text { about things? }\end{array}$ & 1 & 2 & 3 & 4 \\
\hline $\begin{array}{l}\text { 3. How much can you rely on them for help if you } \\
\text { have a serious problem? }\end{array}$ & 1 & 2 & 3 & 4 \\
\hline $\begin{array}{l}\text { 4. How much can you open up to them if you need to } \\
\text { talk about your worries? }\end{array}$ & 1 & 2 & 3 & 4 \\
\hline
\end{tabular}

Note. Modified measure from Schuster, Kessler, \& Aseltine (1990). 
Appendix D: Functional Limitations Scale

\begin{tabular}{llllc}
\hline & Not at all & A little & Some & A lot \\
\hline $\begin{array}{l}\text { How much does your health limit you in doing each of } \\
\text { the following? }\end{array}$ & & & & \\
\hline a. Lifting of carrying groceries & 1 & 2 & 3 & 4 \\
$\quad$ b. Bathing or dressing yourself & 1 & 2 & 3 & 4 \\
c. Climbing several slights of stairs & 1 & 2 & 3 & 4 \\
d. Bending, kneeling, or stooping & 1 & 2 & 3 & 4 \\
e. Walking more than one mile & 1 & 2 & 3 & 4 \\
f. Walking several blocks & 1 & 2 & 3 & 4 \\
g. Walking one block & 1 & 2 & 3 & 4 \\
h. Vigorous activity (e.g. running, lifting heavy & 1 & 2 & 3 & 4 \\
objects) & & & & \\
i. Moderate activity (e.g. bowling, vacuuming) & 1 & 2 & 3 & 4 \\
\hline
\end{tabular}

Note. Measure from Ware and Sherbourne (1992). 
Appendix E: Comparing Functional Limitation Scores for Older Versus Younger Adults

\begin{tabular}{|c|c|c|c|c|}
\hline & \multicolumn{2}{|c|}{ Younger Aged } & \multicolumn{2}{|c|}{ Older Aged } \\
\hline & Mean & $\underline{S D}$ & Mean & $\underline{S D}$ \\
\hline Lifting or carrying groceries & 1.31 & .752 & 1.62 & .973 \\
\hline Bathing or dressing yourself & 1.11 & .466 & 1.19 & .579 \\
\hline Climbing several flights of stairs & 1.40 & .802 & 1.80 & 1.050 \\
\hline Bending, kneeling, or stooping & 1.45 & .830 & 1.92 & 1.029 \\
\hline Walking more than a mile & 1.40 & .819 & 1.82 & 1.114 \\
\hline Walking several blocks & 1.28 & .711 & 1.60 & .989 \\
\hline Walking one block & 1.16 & .558 & 1.34 & .789 \\
\hline $\begin{array}{l}\text { Vigorous activity (e.g., running, } \\
\text { lifting heavy objects) }\end{array}$ & 1.89 & 1.042 & 2.62 & 1.144 \\
\hline $\begin{array}{l}\text { Moderate activity (e.g., bowling, } \\
\text { vacuuming) }\end{array}$ & 1.30 & .715 & 1.73 & .997 \\
\hline
\end{tabular}


Appendix F: PROCESS Moderation Effects

Table 2

Results of Age X Personality Moderated Regression Analysis

\begin{tabular}{|llll|}
\hline Interactions & $\beta$ & $S E$ & $p$ \\
\hline Age X Neuroticism & .0014 & .0006 & .0222 \\
\hline Age X Conscientiousness & -.0020 & .0006 & .0013 \\
\hline Age X Extraversion & -.0018 & .0006 & .0047 \\
\hline Age X Agreeableness & .0134 & .0082 & .1009 \\
\hline Age X Openness & -.0040 & .0082 & .6202 \\
\hline
\end{tabular}


